\title{
Tropical Cyclone Initialization with Dynamical Retrieval from a Modified UWPBL Model
}

\author{
Lei-Ming MA \\ Laboratory of Typhoon Forecast Technique/CMA, Shanghai Typhoon Institute, Shanghai, China \\ Key Laboratory of Mesoscale Severe Weather/MOE, School of Atmospheric Sciences, Nanjing University, \\ Nanjing, China \\ and \\ Zhe-Min TAN \\ Key Laboratory of Mesoscale Severe Weather/MOE, School of Atmospheric Sciences, Nanjing University, \\ Nanjing, China \\ (Manuscript received 29 September 2009, in final form 28 June 2010)
}

\begin{abstract}
A new scheme, termed Vortex Initialization with the Assimilation of Retrieved Variables (VIRV), is presented to improve the initialization of regional numerical model for Tropical Cyclone (TC) prediction. In this scheme, the horizontal winds in Planetary Boundary Layer (PBL) and the sea level pressure (SLP), retrieved from Quick Scatterometer (QuikSCAT) data obtained using a modified University of Washington Planetary Boundary Layer (UWPBL) model, are assimilated with a cycled three-dimensional variational (3DVAR) technique to produce the initialized analysis. The procedures of retrieval are implemented under the joint dynamical constraints of the gradient wind, secondary circulation, and thermal stratification. Moreover, in order to improve the analysis of TC intensity, the roughness parameterization in the UWPBL model was modified for the case of strong surface wind. The sensitivities of the structure, intensity, and track of TC to the VIRV are then examined by two numerical experiments for TC Bilis (2006) and TC Fung-wong (2008).

The maximum Wind Speed (MWS) and minimum Sea Level Pressure (MSLP) retrieved from the QuikSCAT data obtained using the modified UWPBL model show more agreement with the observations relative to those derived from the analysis of the National Center for Environmental Prediction (NCEP global model). The analysis of TC intensity cfm enhanced using VIRV by modifying the low-level (upper-level) convergence (divergence), vertical shear of horizontal wind, transportation of moisture. Significant improvement on 48-h TC simulation is identified in the MWS, with $22.8 \%$ error reduction. In particular, the Modification of Roughness Parameterization (MRP) enhanced the simulation of MWS by $6.9 \%$. Finally, the VIRV also reduces the simulation error in the track of TC by affecting the steering flow throughout the troposphere.
\end{abstract}

Key words: Tropical cyclone; QuikSCAT; Boundary layer; Retrieval; Data assimilation; Model initialization.

Corresponding author: Lei-Ming $\mathrm{Ma}$, Laboratory of Typhoon Forecast Technique/CMA, Shanghai Typhoon Institute, 166 Puxi Rd., Shanghai 200030, P. R. China. E-mail: malm@mail.typhoon.gov.cn

(C) 2010, Meteorological Society of Japan

\section{Introduction}

In contrast to the recent rapid advances in the numerical models study and forecast for tropical cyclone (hereafter, TC), the advance in vortex initialization for TC is relatively slow. Because of the insufficient observations over the ocean, the approaches that mainly rely on bogus vortex was designed for $\mathrm{TC}$ vortex initialization on the basis 
of limited observations, for example: 1) implanting the model's initial fields into a synthetic (bogus) vortex (i.e., Kurihara et al. 1990; Leslie and Holland 1995) or a "spin-up" vortex produced by a previous forecast of numerical model (Kurihara et al. 1995); 2) vortex initialization with the Bogus Data Assimilation (BDA) during the minimization of a cost function (i.e., Zou and Xiao 2000; Xiao et al. 2000). In these schemes, however, the empirical assumption of TC structure will ultimately lead to unrealistic analysis and forecast of TC.

In recent years, to avoid the deficiency of bogus assumption, more and more data assimilation techniques, focusing on newly-developed datasets and observational strategies, have been applied in TC initialization. For example, Chen et al. (2008) explored hurricane initialization and simulation with the application of precipitable water derived from the Moderate Resolution Imaging Spectroradiometer (MODIS). Ma et al. (2006, 2007) initiated TC through Four-Dimensional Variational data assimilation (4DVAR) and adjustment of adiabatic heating with Tropical Rainfall Measuring Mission (TRMM) rainfall data on the basis of the idea of physical initialization (i.e., Krishnamurti et al. 1991, 1996, 1998). A number of studies found the positive effects of data assimilation on TC numerical prediction with Airborne Doppler Radar (ADR) (Zhao and Jin 2008; Xiao et al. 2009), Dropwindsonde Observations for Typhoon Surveillance near the Taiwan Region (DOTSTAR) (Wu et al. 2007; Chuo and $\mathrm{Wu}$ 2008; Yamaguchi et al. 2009), and aircraft observation with subjective optimal observing strategies (Aberson 2003).

Despite these successful applications, nearly all the above datasets provide negligible or very limited information of Plane Boundary Layer (PBL) of TC, which, acting as the interface for oceanatmosphere energy exchange, plays a dominant role in TC development (Emanuel 1986; Ma et al. 2002; Powell et al. 2003; Tang and Tan 2006; Black et al. 2007). Fortunately, the global sea-level winds obtained from QuikSCAT provide a good opportunity to understand the role of ocean-atmosphere interaction in TC development. Pu and Braun (2001) suggested the QuikSCAT satellite data has a potential for TC initialization, particularly when sea surface pressure information is unavailable. Recently, the University of Washington Planetary Boundary Layer (UWPBL) model (Patoux et al. 2003, 2008), relating the surface pressure gradients to surface winds, which is based on a mixed-layer theory, is used to retrieve dynamical-balanced PBL winds and SLP from QuikSCAT wind vectors (Stevens et al. 2002). By reducing the negative effects of rainfall contamination on the original QuikSCAT winds (Stiles and Yueh 2002), the derivation and analysis of TC dynamic structure using the UWPBL should be helpful for TC initialization and prediction.

Before using the UWPBL model, however, a controversial relationship between roughness (drag coefficient) and surface wind in the parameterization of the UWPBL is noticed, which contradicts the results of recent observational (e.g., Powell et al. 2003) and numerical studies (e.g., Moon et al. 2007; hereafter, M07). On the basis of modification of roughness parameterization (MRP) of the UWPBL model, this study attempts to improve the model initialization by using the winds and Sea Level Pressure (SLP) fields retrieved from QuikSCAT data. The initialization method is termed Vortex Initialization with the Assimilation of Retrieved Variables (VIRV). Section 2 describes the data and methodology. The numerical verifications of the new scheme, as well as the sensitivities of the TC structure, track, and intensity to the new initialization scheme are examined in Section 3 and 4. The summary is finally given in Section 5.

\section{Data and methodology}

\subsection{Data}

The QuikSCAT level-2B surface wind datasets were provided by the Physical Oceanography Distributed Active Archive Center (PODAAC) of USA JPL/NASA. The surface winds are gridded every $25 \mathrm{~km}$, and postprocessing has produced $12.5 \mathrm{~km}$ retrievals in near-real time since the year 2003. The swath of QuikSCAT retrievals is $1800 \mathrm{~km}$, resulting in a coverage of about $90 \%$ of the global oceans each day. A detailed description of the QuikSCAT platform is given in Hoffman and Leidner (2005). Most recently, Chou et al. (2010) verified QuikSCAT wind vectors near TCs against soundings of GPS dropwindsondes deployed by DOTSTAR during 2003 and 2007. They found that the QuikSCAT data slightly underestimates the wind speed of medium-wind regime (between 10 and $17.2 \mathrm{~m} \mathrm{~s}^{-1}$ ) and possesses clockwise directional bias in the high-wind regime (above $17.2 \mathrm{~m} \mathrm{~s}^{-1}$ ). Moreover, the QuikSCAT wind vectors below tropical storm wind strength are accurate enough for forecasters to determine the critical wind radius (Chou et al. 2010). 
In this study, the QuikSCAT wind vectors are interpolated onto the grid on which the UWPBL model is run. The reference pressure data for the UWPBL model is obtained from the National Data Buoy Center (NDBC) of NOAA. The background field of mesoscale model for TC simulation is provided by the NCEP Global Forecast System (GFS) (horizontal resolution is $1.0^{\circ}$ ). The observed TC intensity is issued by the Joint Typhoon Warning Center (JTWC). Instead of monthly-mean winds obtained from the NOAA Climate Diagnostics Center (CDC), the 925-hPa winds analyzed by GFS/NCEP model are used to estimate the freetropospheric wind according to the deficiency of climatological data (Patoux et al. 2003). Instead of TRMM (for its limitation of spatial coverage), Infrared (IR) cloud top temperature data from FengYun-2C (FY-2C) geostationary meteorological satellite (Xu et al. 2006), operated by China Meteorological Administration (CMA), is used to verify the simulated $\mathrm{TC}$ structure. In addition, the NCEP reanalysis data (resolution of $2.5^{\circ}$ ) is employed for the verification on the simulation of Convective Available Potential Energy (CAPE).

The TC Bilis (2006) and TC Fung-wong (2008) that occurred over the northwestern Pacific in 2006 and 2008, respectively, are selected for evaluation of the VIRV. There are two reasons for selecting these TC cases: 1) Bilis (2006) maintained its intensity (about $975 \mathrm{hPa}$ ) for an unexpectedly long period when it passed through Taiwan island and ultimately made landfall on China mainland and brought to China the most serious TC disaster in the last 50 years; 2) in contrast to Bilis (2006), the more intensive TC Fung-wong (2008) experienced a rapid-weakening phase when it passed through Taiwan island. The two cases are therefore appropriate for the verification of VIRV for the analysis and simulation of TC intensity.

\subsection{Methodology}

The methodologies of dynamical retrieval with the UWPBL model, MRP of UWPBL in the case of strong wind, and the design of VIRV are particularly introduced in this section.

\section{a. Dynamical retrieval using the UWPBL model}

For strongly curved flows such as TC circulation, the centrifugal acceleration is as important as the pressure gradient force. Therefore, a three-force balance, referred to as the gradient wind (e.g., Holton 1992), must be established to calculate the actual wind vector. In this study, the UWPBL model and its inverse model is used to calculate the gradient wind vectors using the surface wind vectors. In this model, at each model grid for which a QuikSCAT surface wind vector is available, a PBL wind profile is approximated by patching a modified Ekman spiral to a logarithmic surface layer with the special treatment of stratification and baroclinicity (Foster et al. 1999). Derived from this wind profile, the PBL flow is separated into primary flow (or mean flow) or secondary flow (or zero-mean finite perturbation flow). Here, the secondary flow is parameterized as an equilibrium perturbation to represent the activity of PBL rolls (Brown 1970, 1981; Black et al. 2007). The amplitude of this perturbation is determined by an equilibrium energy balance. The consequence of this parameterized secondary flow is more thorough mixing throughout the PBL with higher gradients near the bottom and top; therefore, the UWPBL model produces higher surface winds and heat fluxes than diffusion models (Patoux et al. 2003). The ocean mixing beneath TC circulation then significantly reduces sea surface temperatures and enthalpy flux (Black et al. 2007).

The retrieval of oceanic surface pressure field is implemented in four steps (Patoux 2000): 1) in the mid-latitudes, the surface pressure gradients are obtained with an inversed two-layer-similarity PBL model; 2) in the tropics, an inversed mixed-layer model is employed to estimate the pressure gradients; 3) the surface pressure fields are then derived from the pressure gradient fields by least-squares optimization; 4) the tropical PBL model is then combined with the mid-latitude model to provide a continuous global surface pressure.

In the two-layer-similarity PBL model designed for the mid-latitudes (Patoux 2000), the geostrophic wind $(G)$ at the top of PBL can be calculated once the surface wind $\left(U_{h}\right)$ is given, as below:

$$
\frac{U_{h}}{G}=\frac{V_{T}}{G}+\frac{1}{G} \frac{\partial V_{2}}{\partial \xi}+\cos \alpha+\sin \alpha,
$$

where $V_{T}$ is the thermal wind correction, $V_{2}$ the secondary circulation, $\alpha$ the wind turning angle within the PBL. Gradient wind vector can then be estimated from $G$ using the gradient wind correction approach (Patoux and Brown 2002).

In the tropics, a simple mixed-layer model is employed to integrate the steady-state balance equations over the depth of the boundary layer. To obtain the first wind profile, the first guess on the pressure gradient is assumed to be constant 
throughout the boundary layer. The bulk wind is calculated by integration of this profile, and a new estimate of the pressure gradient is obtained from the bulk force balance as follows,

$$
\begin{aligned}
& \frac{P_{x}}{\rho}=f V-\frac{w_{e}}{h}\left(U_{T}-U\right)+\frac{u_{*}^{2}}{h} \frac{u_{10}}{\left|\overline{\bar{u}}_{10}\right|}, \\
& \frac{P_{y}}{\rho}=-f U-\frac{w_{e}}{h}\left(V_{T}-V\right)+\frac{u_{*}^{2}}{h} \frac{v_{10}}{\left|\overline{\bar{u}}_{10}\right|} .
\end{aligned}
$$

where $h$ is $500 \mathrm{~m}$, and $w_{e}$ is $1.00 \mathrm{~cm} \mathrm{~s}^{-1}$. The final value for the pressure gradient is obtained by convergence from a few iterations.

These two models yield pressure gradients in the mid-latitudes $\left(60^{\circ} \mathrm{S}\right.$ to $10^{\circ} \mathrm{S}$ and from $10^{\circ} \mathrm{N}$ to $60^{\circ} \mathrm{N}$ ) and the tropics (from $20^{\circ} \mathrm{S}$ to $20^{\circ} \mathrm{N}$ ). At each point of the corresponding grids, the pressure gradient is connected to the pressure by leastsquares optimization (Brown and Zeng 1994). The pressure fields are finally blended in the overlapping latitudinal bands between the tropical and mid-latitudes (Patoux et al. 2003).

\section{b. MRP in the high wind speed}

Numerical experiments indicate that the simulated TC intensity is largely determined by seasurface fluxes (e.g., Braun and Tao 2000). Although TC intensity increases with the ratio between the exchange coefficients for enthalpy and momentum, the simulated TC intensity varies depending on the relationship between the wind speed, surface roughness, and drag coefficient $\left(C_{d}\right)$. Generally, $C_{d}$ is assumed to increase linearly with weak-to-moderate wind speed. In strong wind conditions, the $C_{d^{-}}$ wind relationship is derived by linear extrapolation from weak-to-moderate wind regimes, which are currently used in the UWPBL.

However, by using the wind profiles measured by the Global Positioning System (GPS) in the vicinity of the hurricane eyewalls, Powell et al. (2003) found that surface momentum flux levels off as the surface wind speeds increase above the hurricane force. This result has been supported by more and more theoretical and numerical studies (e.g., Emanuel 2003; Makin 2005; Moon et al. 2004a, b, c; Black et al. 2007). An explanation for this result, as given by Powell et al. (2003), is the development of a sea foam layer at the air-sea interface. This sea foam layer, as the intensity of surface wind approaches a certain value, will impede the air-sea momentum exchange. Nevertheless, the amount of "level off" and the wind speed at which the "level off" occurs remains uncertain (French et al. 2007). For example, Black et al. (2007) suggest "level off" with the surface wind speed near $22-23 \mathrm{~m} \mathrm{~s}^{-1}$, which is significantly lower than that (i.e., $33 \mathrm{~m} \mathrm{~s}^{-1}$ ) of Powell et al. (2003).

The neutral $C_{d}$ as a function of the roughness length $z_{0}$ is defined as:

$$
C_{d}=k^{2}\left(\ln \frac{10}{z_{0}}\right)^{-2},
$$

where $k$ is the von Kármán constant. In the present study, $k=0.4$.

In the UWPBL, $z_{0}$ is parameterized by:

$$
z_{0}=a \frac{u_{*}^{2}}{g}+b \frac{v}{u_{*}},
$$

where $a$ and $b$ are constant and given by data statistics (Miller and Katsaros 1992; Smith 1988), $v$ is the dynamical frictional coefficient $\left(1.34 \times 10^{-5} \mathrm{~m}^{2} \mathrm{~s}^{-1}\right)$.

According to the "level-off" phenomenon, M07 presented a new roughness parameterization scheme on the basis of numerical experiments using an atmosphere-ocean coupled model. $z_{0}$ is parameterized as:

$$
\begin{aligned}
z_{0}= & \frac{0.0185}{g} u_{*}^{2}, \quad W \leq 12.5 \mathrm{~ms}^{-1} \\
z_{0}= & {\left[0.085\left(-0.56 u_{*}^{2}+20.255 u_{*}+2.458\right)\right.} \\
& -0.58] \times 10^{-3}, \quad W>12.5 \mathrm{~ms}^{-1} .
\end{aligned}
$$

where $W$ is the surface wind speed.

$C_{d}$ is then calculated by an iteration procedure using stability parameters and universal functions on the basis of the Monin-Obukhov similarity theory (Liu et al. 1979). Experiments using the operational Geophysical Fluid Dynamics Laboratory (GFDL) hurricane model show the advantages of the M07 scheme in the prediction of MWS. Therefore, the M07 scheme is used in this study to update the UWPBL model.

\section{c. The VIRV scheme}

For its successful application in TC prediction (Xiao et al. 2009), the Weather Research and Forecasting model/Three-Dimensional Variational data assimilation system (WRF/3DVAR, Skamarock et al. 2005), developed by the National Center for Atmospheric Research (NCAR), is used for the design of VIRV. The WRF/3DVAR can produce balanced multivariate analysis subject to embedded dynamical and statistical constraints. The WRF/ 
3DVAR is achieved by the minimization of a predefined cost function $J(x)$, combined by observational and background error, to get an optimal analysis for the initial condition $(x)$. The preconditioning control variables in WRF/3DVAR include streamfunction, unbalanced velocity potential, unbalanced temperature, pseudo-relative humidity, and unbalanced surface pressure.

The cost function $J(x)$ for the assimilation of SLP and horizontal winds is defined in this study as:

$$
J(x)=J_{b}+J_{p}+J_{v},
$$

where,

$$
\begin{aligned}
J_{b} & =\frac{1}{2}\left(x-x_{b}\right)^{T} B^{-1}\left(x-x_{b}\right), \\
J_{p} & =\sum_{\Omega}\left(P-P_{o}\right)^{T} W_{p}^{-1}\left(P-P_{o}\right), \\
J_{v} & =\sum_{\Omega}\left(V-V_{o}\right)^{T} W_{v}^{-1}\left(V-V_{o}\right),
\end{aligned}
$$

and $x_{b}$ is the background field; $P_{o}$ is the SLP retrieved from QuikSCAT sea winds $V_{o}$ is the horizontal wind fields ( $u$ and $v$ components) retrieved from QuikSCAT. $W_{p}$ and $W_{v}$ are the diagonal error variance matrices for the SLP and horizontal wind fields retrieved using the UWPBL, respectively. $\Omega$ is the region covered by QuikSCAT data. The observational operator for SLP is designed on the basis of Dudhia et al. (2002).

The observational and background error covariance assumes Gaussian probability distribution, ignoring the relationship between the observation and background error. A quasi-newton method (Liu and Nocedal 1989) is used to minimize the cost function to make an optimal analysis. Since the background error covariance produced by the NMC method (Parrish and Derber 1992) might not be appropriate for the case of TCs (Xiao et al. 2006), it is estimated by ensemble predictions based on WRF model (12 ensemble members considering the uncertainties of PBL parameterization schemes). The variable adjustment and the propagation of information from one variable to another are based on the background error covariance structure, and balance equations in the 3DVAR system (Barker et al. 2004). The observation errors for the retrieved SLP and wind are subjectively assigned similar to the scheme of Xiao et al. (2006) in which a smaller error is specified in the vicinity of the TC center, which implies more contribution from the data retrieved near the TC center. The SLP and winds retrieved from the UWPBL are simultaneously assimilated in this study. Although Wu et al. (2006, hereafter, W06) suggest that, due to the geostrophic adjustment, the assimilation of wind fields is more efficient than that of pressure fields in improving the initial structure of TCs; both pressure and wind observation data are still necessary for vortex initialization to obtain a better forecast (Xiao et al. 2000). Pu and Braun (2001) also found that only when both the bogus SLP and wind are assimilated does the model produce a vortex consistent with the actual intensity. A cycled3DVAR procedure is designed for VIRV and illustrated in Fig. 1. In this scheme, the assimilation of retrieved variables is performed twice during the 12-h initialization cycle. The forecast from the previous 12-h cycle serves as the background for the second time of assimilation. Once the VIRV procedure is completed, a 48-h simulation is performed to examine its impacts on TC prediction.

\section{Retrieval and analysis with the VIRV}

\subsection{Design of numerical experiments}

Numerical experiments using the WRF model have shown some promise in forecasting TCs near landfall (Davis et al. 2008). In this study, a series of numerical experiments are designed and performed with the WRF model Version 3.1. The control experiment (CTRL) uses the background fields from NCEP/GFS with no additional observation assimilated. Two sensitivity experiments (REXP1: initialization with the retrieval from the original UWPBL model; REXP2: initialization with the retrieval from the modified UWPBL model in the present study) were conducted for comparison. The times for analysis are 1200 UTC on July 27, 2008 and 1200 UTC on July 12, 2006 for the TC Fungwong (2008) and TC Bilis (2006), respectively.

A total of 27 sigma $(\sigma)$ levels were designed, with the model top at $10 \mathrm{hPa}$. More than seven sigma layers are located between the sea surface and $1.5 \mathrm{~km}$ height for a detailed description of the PBL structure. The model has a single fixed domain (Fig. 2) with dimension of $271 \times 271$ and horizontal resolution of $12 \mathrm{~km}$. The model water cycle processes are represented by Kain-Fritsch cumulus parameterization scheme and Single-Moment threeclass (WSM3) microphysics scheme (Hong et al. 2004). Yonsei University (YSU) scheme is employed to describe the PBL processes (Noh et al. 2003; Hong et al. 2006). This scheme is a first-order 


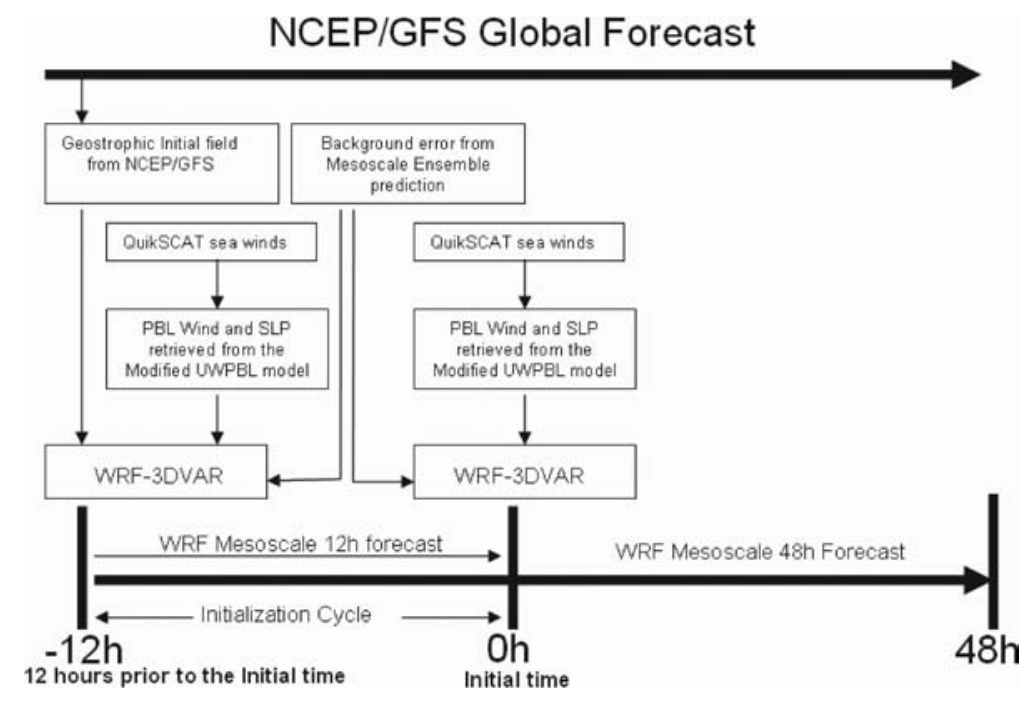

Fig. 1. Diagram of the VIRV scheme. NCEP/GFS Global Forecast provides the background field for TC initialization, which is interpolated into the $12 \mathrm{~km}$ grid of WRF-3DVAR that is consistent with the WRF model. At the 12 hours (denoted by " $-12 \mathrm{~h}$ ") prior to the initial time for prediction, the PBL winds as well as the SLP fields, retrieved from QuikSCAT data with the modified UWPBL model, are assimilated into the WRF-3DVAR system. The WRF model is then initialized the first time at " $-12 \mathrm{~h}$ ". A subsequent 12 hours forecast is made following this initialization. At the end of the 12 hours simulation (also the initial time denoted by " $0 \mathrm{~h}$ "), the retrieved PBL wind and SLP fields are assimilated the second time to make the final analysis for the WRF mesoscale $48 \mathrm{~h}$ forecast.

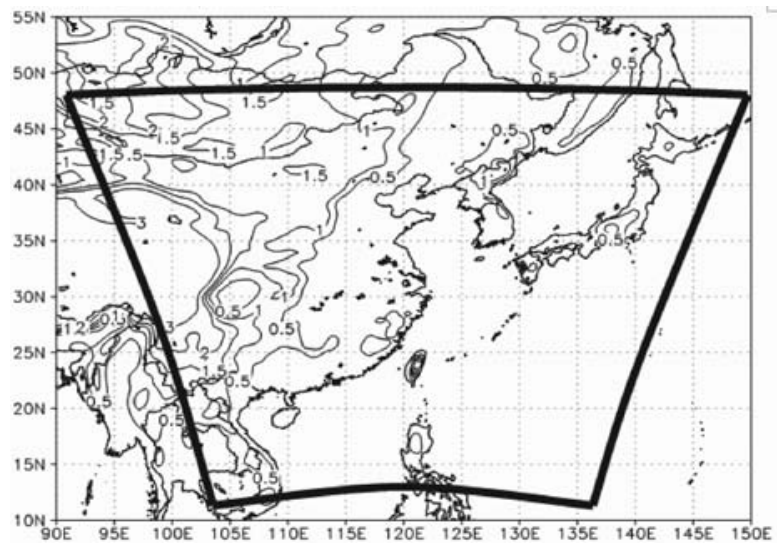

Fig. 2. The model domain designed for numerical experiments. The lateral boundary of the domain is indicated by the thick lines, with the terrain heights $0.5 \mathrm{~km}$, $1.0 \mathrm{~km}, 1.5 \mathrm{~km}, 2.0 \mathrm{~km}$, and $3.0 \mathrm{~km}$ shown in contours.

closure scheme similar in concept to the MediumRange Forecast (MRF) PBL scheme (Hong and Pan 1996) but less biased toward excessive vertical mixing (Braun and Tao 2000). In particular, with a revised vertical diffusion package, the YSU PBL scheme increases (decreases) the boundary-layer mixing in the thermally induced free convection regime (the mechanically induced forced convection regime), in comparison with that of the MRF scheme.

\subsection{Retrieval with the VIRV}

The retrieved wind in the PBL (Fig. 3) and SLP fields reveal an evident depression to Taiwan Island and a subtropical high to the north of the depression. The retrieved SLP also indicates a southward displacement of subtropical high in comparison with that of NCEP/GFS (not given). The intensities of the TCs Fung-wong and Bilis are reproduced well by the modified UWPBL model. Specifically, the magnitude (coverage) of the retrieved maximum wind in the vicinity of the TC center is significantly larger than the original QuikSCAT observation. The maximum wind observed by QuikSCAT and retrieved using the UWPBL model for Fung-wong at 1000 UTC on July 27, 2008 is $24 \mathrm{~m} \mathrm{~s}^{-1}$ and $33 \mathrm{~m} \mathrm{~s}^{-1}$, respectively, while for TC Bilis, at 1000 UTC on July 12, 2006, the retrieved maximum 

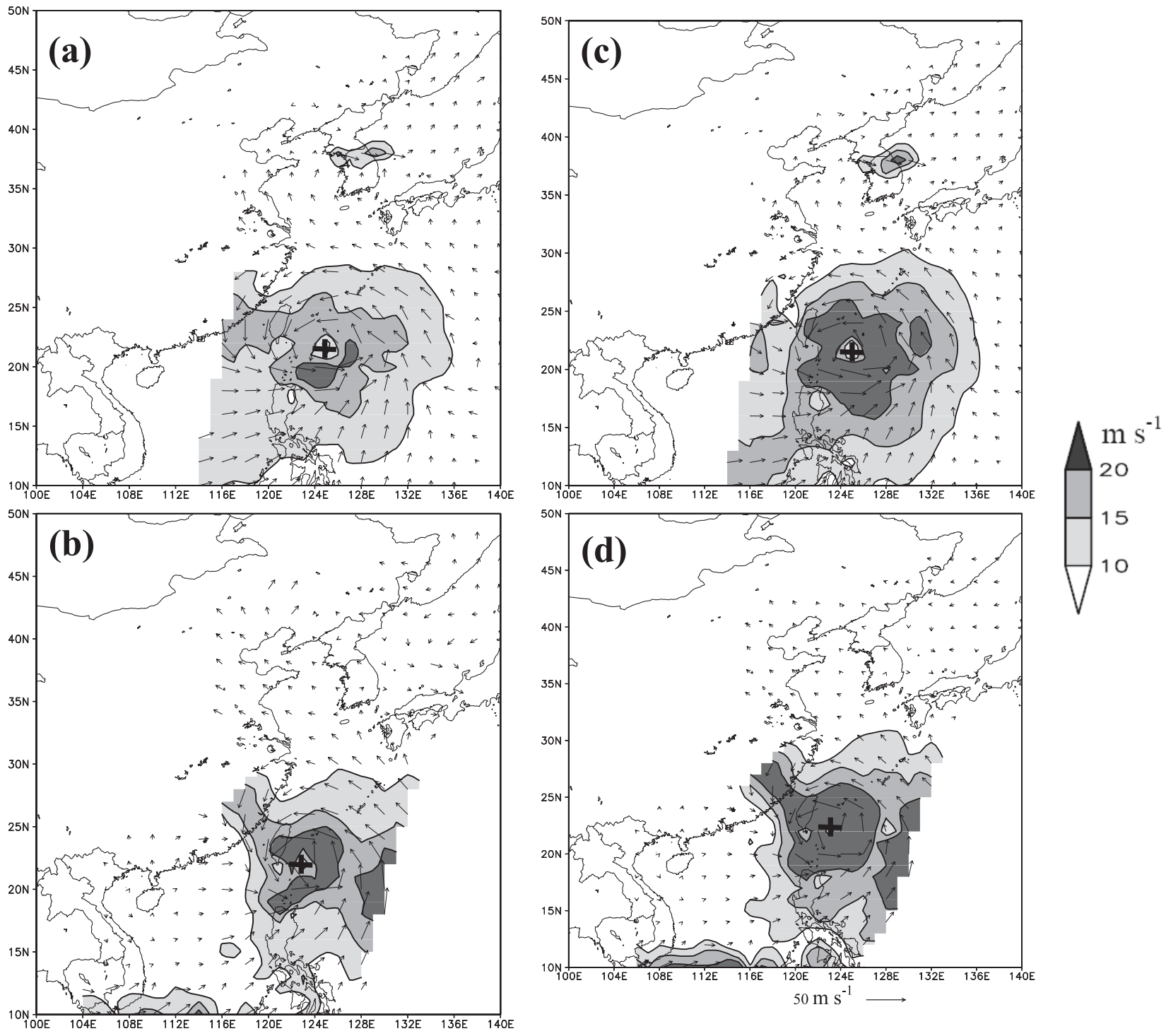

Fig. 3. QuikSCAT sea wind speeds $\left(10 \mathrm{~m} \mathrm{~s}^{-1}, 15 \mathrm{~m} \mathrm{~s}^{-1}\right.$, and $20 \mathrm{~m} \mathrm{~s}^{-1}$ are shaded) and vectors at $10 \mathrm{~m}$ above the sea surface. (a) 1000 UTC 12 Jul. 2006 for TC Billis, (b) 1000 UTC 27 Jul. 2008 for TC Fung-wong (c) same as (a), and (d) same as (b), but for the wind speeds and vectors at the top of the PBL retrieved by the UWPBL model. The center of TC is marked by a thick cross. The blank region is not covered by the orbit of QuikSCAT.

wind $\left(30 \mathrm{~m} \mathrm{~s}^{-1}\right)$ is $42.8 \%$ greater than that of the QuikSCAT wind $\left(21 \mathrm{~m} \mathrm{~s}^{-1}\right)$. The retrieved winds show consistency with the observation $\left(36 \mathrm{~m} \mathrm{~s}^{-1}\right.$ and $31 \mathrm{~m} \mathrm{~s}^{-1}$ for Fung-wong and Bilis, respectively). The magnitudes of the retrieved minimum SLP are also deeper than those of the NCEP/GFS analysis.

The structures of TC PBL (e.g., Ekman depth, frictional velocity, and surface stress) are also retrieved and examined to evaluate the performance of the modified UWPBL model (not shown). It is found that all these PBL variables are generally higher in the vicinity of the TC center and lower in the outer region of $\mathrm{TC}$ circulation. The vigorous convection in the TC core region may favor the ocean-air momentum mixing over there. Although 
more intensive ocean-atmosphere dynamical mixing is identified for Bilis, the intensity of Fungwong was much stronger (than Bilis) due to the following two-fold effects of the ocean (Powell et al. 2003; Black et al. 2007): 1) intensifying of the TC by the surface heat flux; 2) weakening of the TC by ocean spray and overturning (either weakens the PBL wind or cools the PBL atmosphere). The MRP intensifies the sensible heating flux mainly in the area of intensive wind. The reduction of oceanair PBL momentum mixing intensifies the oceanatmosphere humidity gradient, favoring the latent heating flux from the ocean to the air. However, the sensible heating flux (nearly $30 \%$ of latent heating) exhibits negligible change due to the MRP of the UWPBL model. One of the reasons might be that the decrease of ocean-atmosphere vertical momentum flux favors the accumulation of oceanatmosphere temperature gradient. As a result, the balance between the enhanced temperature gradient and the weakened ocean-atmosphere mixing ensure the temperature advection an approximate constant.

\subsection{Analysis with the VIRV}

In a previous study on bogus vortex 4DVAR, $\mathrm{Pu}$ and Braun (2001; hereafter, PB01) suggested that the effects of including gradient wind information are equivalent to introducing a gradient balance constraint during data assimilation. It forces the vortex wind field to be consistent with the gradient balance relationship, and allows the system to reproduce both rotational and convergent components of the wind field. In this sense, the VIRV, although using the constraint of 3DVAR, has some similar effect as that of 4DVAR, because the full model dynamics is introduced within the 12-h initialization cycle of VIRV. Figures $4 a-c$ shows the difference fields of wind between REXP1 and CTRL (REXP1 minus CTRL) at various pressure levels. It indicates that the convergence is enhanced around the TC center at $850 \mathrm{hPa}$ (Fig. 4a) and $500 \mathrm{hPa}$ (Fig. 4b). In response to this enhanced convergence, a divergent circulation is generated over the high troposphere (Fig. 4c). Meanwhile, a number of mesoscale cyclonical vortices are also generated to the south and southwest of the TC center (Fig. 4b).

Figures $5 \mathrm{a}-\mathrm{d}$ show the vertical cross sections of the difference fields of horizontal wind, potential temperature, and vertical velocities between CTRL and REXP2 (REXP2 minus CTRL) through the center of Fung-wong (2006). Consistent with the asymmetric structure of wind (Fig. 3) and the deepened SLP retrieved by the modified UWPBL model, the difference field of U-wind (Fig. 5a) depicts stronger convergence (divergence) below (above) $400 \mathrm{hPa}$, with intensified U-wind to the east of the TC center. Moreover, under the constraint of assimilation, the radius of the maximum wind is reduced by about $10 \%$.

The V-wind difference fields also show stronger convergence surrounding the TC center due to VIRV (Fig. 5b), with a well-developed asymmetric vortex. The horizontal wind difference is greater than $16 \mathrm{~m} \mathrm{~s}^{-1}$ at the southern portion, and only $10 \mathrm{~m} \mathrm{~s}^{-1}$ at the northern portion of TC. VIRV leads to warmer potential temperature anomaly (Fig. 5c) and stronger upward motion (Fig. 5d) around the center of the storm; with the maximum upward motion is about $1.8 \mathrm{~m} \mathrm{~s}^{-1}$ at $200-300 \mathrm{hPa}$ and the maximum warm anomaly is about $1.5 \mathrm{~K}$ at $300-400 \mathrm{hPa}$. Six hours later, the low-level (highlevel) convergence (divergence), vertical motion, as well as the TC warm core, is significantly enhanced (figure is not given). This similar change of warm core and vertical motion due to the assimilation of wind and pressure was also noticed by PB01, which is more evident than that of the assimilation of wind only (Xiao et al. 2000; hearafter, X00).

It is widely accepted that Vertical Shear of Horizontal wind (hereafter, VSW) is a major factor in the intensity change of TCs (e.g., DeMaria and Kaplan 1999; Fitzpatrick 1997; Hanley et al. 2001; Paterson 2005). As suggested by Paterson (2005), typically a critical VSW of $10 \mathrm{~m} \mathrm{~s}^{-1}$ represents a transition from intensification to weakening (i.e., VSW values of less than $10 \mathrm{~m} \mathrm{~s}^{-1}$ favor intensification). The VSW is also a dominant factor in the formation of precipitation asymmetries in TCs (e.g., Willoughby et al. 1984; Marks et al. 1992; Franklin et al. 1993; Bender 1997; Frank and Ritchie 1999, 2001, 2002). The precipitation in TCs (away from the land) tends to be maximized on the left side of the VSW vector (i.e., downshear left). Following Marks et al. (1992) and Rogers et al. (2003), the storm-scale VSW is examined in this study. To locate the TC center, a technique similar to the simplex algorithm of Neldar and Mead (1965) and Marks et al. (1992) is used to locate where the eyewall vorticity is greatest. The vortex winds are then Fourier decomposed into azimuthally averaged (i.e., symmetric) and asymmetric fields (e.g., Marks et al. 1992; Reasor et al. 2000). 

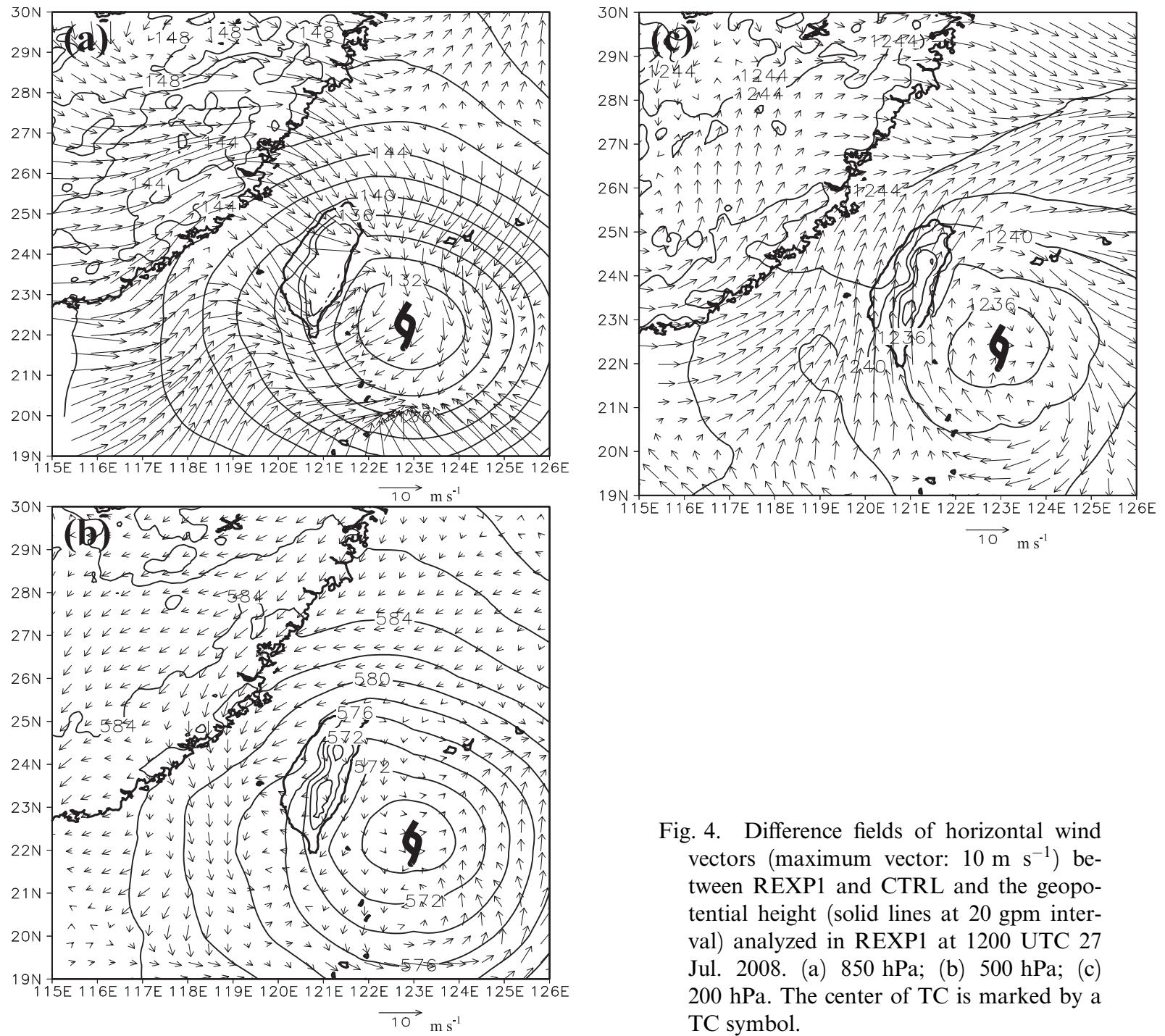

Fig. 4. Difference fields of horizontal wind vectors (maximum vector: $10 \mathrm{~m} \mathrm{~s}^{-1}$ ) between REXP1 and CTRL and the geopotential height (solid lines at 20 gpm interval) analyzed in REXP1 at 1200 UTC 27 Jul. 2008. (a) $850 \mathrm{hPa}$; (b) $500 \mathrm{hPa}$; (c) $200 \mathrm{hPa}$. The center of TC is marked by a TC symbol.

The horizontal storm-relative wind, $V_{s}$, is expressed as

$$
V_{s}(x, y, z)=V(x, y, z)-V_{c}
$$

where $V(x, y, z)$ is the model generated total wind, and $V_{c}$ is the storm motion vector (a spatial constant defined by an objective fit to the trajectory of MSLP). The total storm-relative wind, $V_{s}(x, y, z)$, can be divided into a horizontally averaged component and the deviation from that component:

$$
V_{s}(x, y, z)=\langle V(z)\rangle+V^{*}(x, y, z),
$$

where $\langle V(z)\rangle$ is the horizontal averaged Cartesian coordinate wind vector over a $1000-\mathrm{km}$ horizontal box centered on the TC. This variable provides an approximation of the environmental flow around the storm. The storm-relative VSW is calculated by subtracting the horizontal wind speed at $200 \mathrm{hPa}$ from the one at $850 \mathrm{hPa}$ for both the $u$-component and $v$-component of $\langle V(z)\rangle$. It is found that the VIRV slightly enhanced the VSW. Before the assimilation, the storm's precipitation (Fig. 6a) and vertical motion (Fig. 7a) are relatively scattered with weaker VSW $\left(7 \mathrm{~m} \mathrm{~s}^{-1}\right)$. The VSW increases (Fig. $6 \mathrm{~b} ; 9 \mathrm{~m} \mathrm{~s}^{-1}$ ) after the assimilation, while the upward motion (Fig. 7, shaded greater than $0.1 \mathrm{~m} \mathrm{~s}^{-1}$ ) forms preferentially on the downshear side of the TC circulation. Rainfall intensity also increases and become more asymmetric, with the maximum rainfall $\left(50 \mathrm{~mm} 6 \mathrm{~h}^{-1}\right)$ slightly down- 

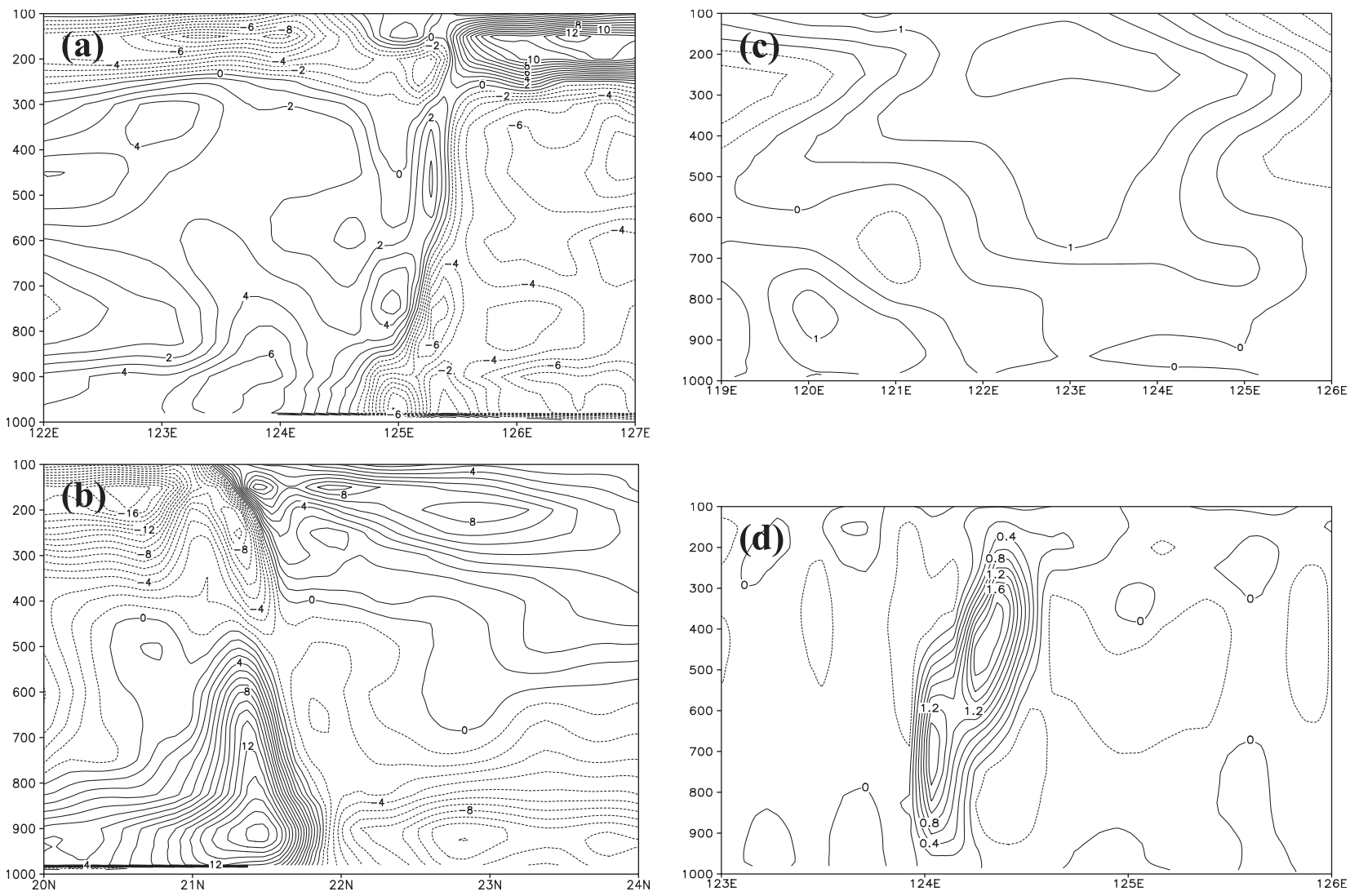

Fig. 5. Cross sections for the difference fields between the CTRL and REXP2 at 1200 UTC 27 Jul. 2008 along the TC center. (a) $u$-component (along $22.2^{\circ} \mathrm{N}$, at interval of $1 \mathrm{~m} \mathrm{~s}^{-1}$ ); (b) $v$-component (along $123.2^{\circ} \mathrm{E}$, at interval of $1 \mathrm{~m} \mathrm{~s}^{-1}$ ); (c) potential temperature (along $22.2^{\circ} \mathrm{N}$, at interval of $0.5 \mathrm{~K}$ ); and (d) vertical motion (along $22.2^{\circ} \mathrm{N}$, at interval of $0.2 \mathrm{~m} \mathrm{~s}^{-1}$ ). Solid (dashed) lines for positive (negative) values.

stream of the upward motion. The region of maximum rainfall shifts from the south (Fig. 6a; CTRL; $\left.122^{\circ} \mathrm{E}-124^{\circ} \mathrm{E}\right)$ to the southeast side of the TC circulation (Fig. 6b; REXP2; $124^{\circ} \mathrm{E}-126^{\circ} \mathrm{E}$ ), generally consistent with the structure of cloud top temperature as captured by the Chinese satellite FY-2C at a close time (Fig. 8). Because of VIRV, the upward motion becomes more organized and slightly intensified with stronger VSW and adjacent evident downward motion just downstream (in a cyclonic sense) of the updraft (Figs. 6, 7). These distribution patterns of vertical motion under the influence of VSW are similar to the results of observation (Marks et al. 1992; Black et al. 2002) and simulation (Braun and $\mathrm{Wu}$ 2007). As simulated by CTRL, the TC circulation contains several scattered areas of concentrated vorticity, with closed circulations in the asymmetric flow field. While in the case of the stronger VSW as reproduced by
REXP2, the mesovortices move cyclonically, mixing and coalescing, and they ultimately form a set of larger scale vortices around the TC center (not given). This effect of VSW was also noticed by Kossin and Schubert (2001) and Montgomery et al. (2002). The process of vortex merger can be understood through the upscale growth of vorticity (well known in two-dimensional turbulence), and has been recognized as an important factor for storm development in western Pacific Ocean (Ritchie and Holland 1997). In contrast to CTRL, REXP2 with strong VSW produces an asymmetric flow across the TC center with considerable mixing of vorticity southwest of TC into the TC center. The asymmetric flow implies that when the shearinduced wavenumber-1 asymmetry becomes large, significant low-level ventilation of the TC circulation (Braun and $\mathrm{Wu} 2007$ ) occurs (on the southwest of the TC in this study). The vorticity to the east 


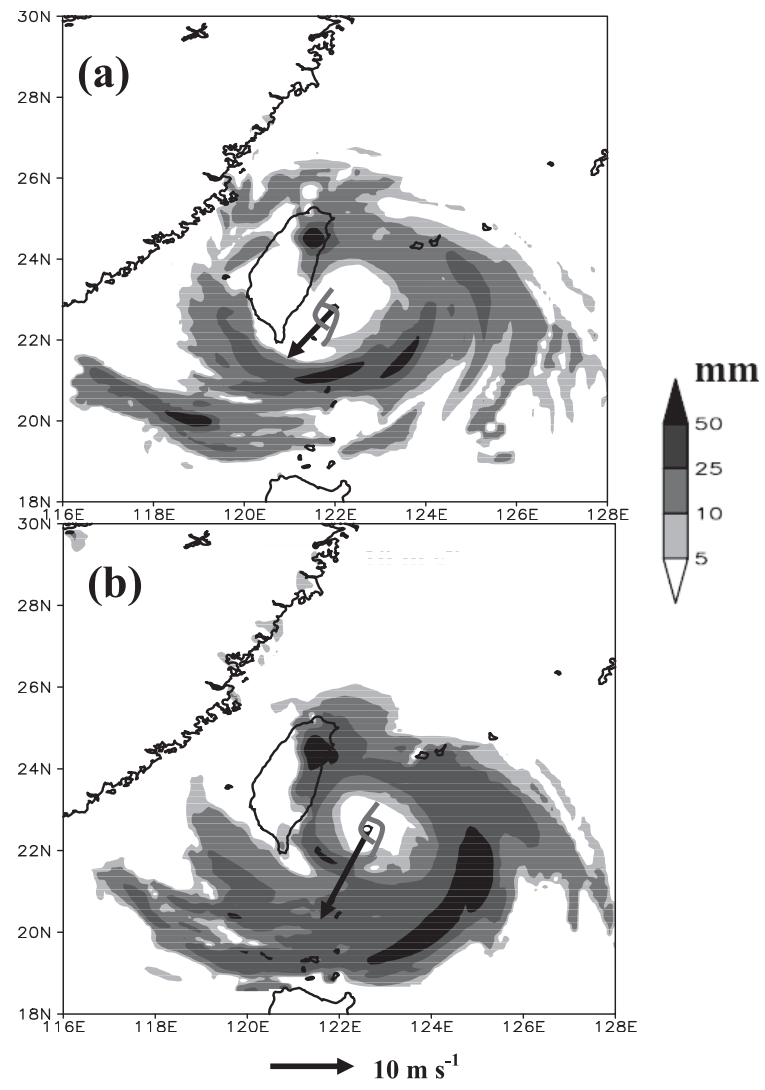

Fig. 6. Total surface rainfall during 1200 UTC-1800 UTC 27 Jul. 2008 for TC Fung-wong (shaded at 5, 10, 25, $50 \mathrm{~mm}$ ) simulated by experiments. (a) CTRL; (b) REXP2. Arrows show the 6-h-averaged $850-200-\mathrm{hPa}$ vertical wind shear vector (the reference shear vector is $10 \mathrm{~m} \mathrm{~s}^{-1}$ ). The center of TC is marked by a TC symbol.

side of the TC circulation increases significantly, suggestive of strong vorticity mixing from the southwestern portion to the TC center, favoring the ultimate intensification of the TC. The CAPE is also examined to evaluate the effect of VIRV on the change of distribution of TC convection. The CAPE simulated in the REXP2 (Fig. 9c) is also compared with that in CTRL (Fig. 9b) and NCEP reanalysis (Fig. 9a). The distribution of CAPE simulated in REXP2 agrees well with that of NCEP reanalysis (especially the low CAPE value within the TC center), although the maximum CAPE of the latter is somewhat underestimated because of the coarse resolution of NCEP reanalysis. In consistency with that of rainfall distribution

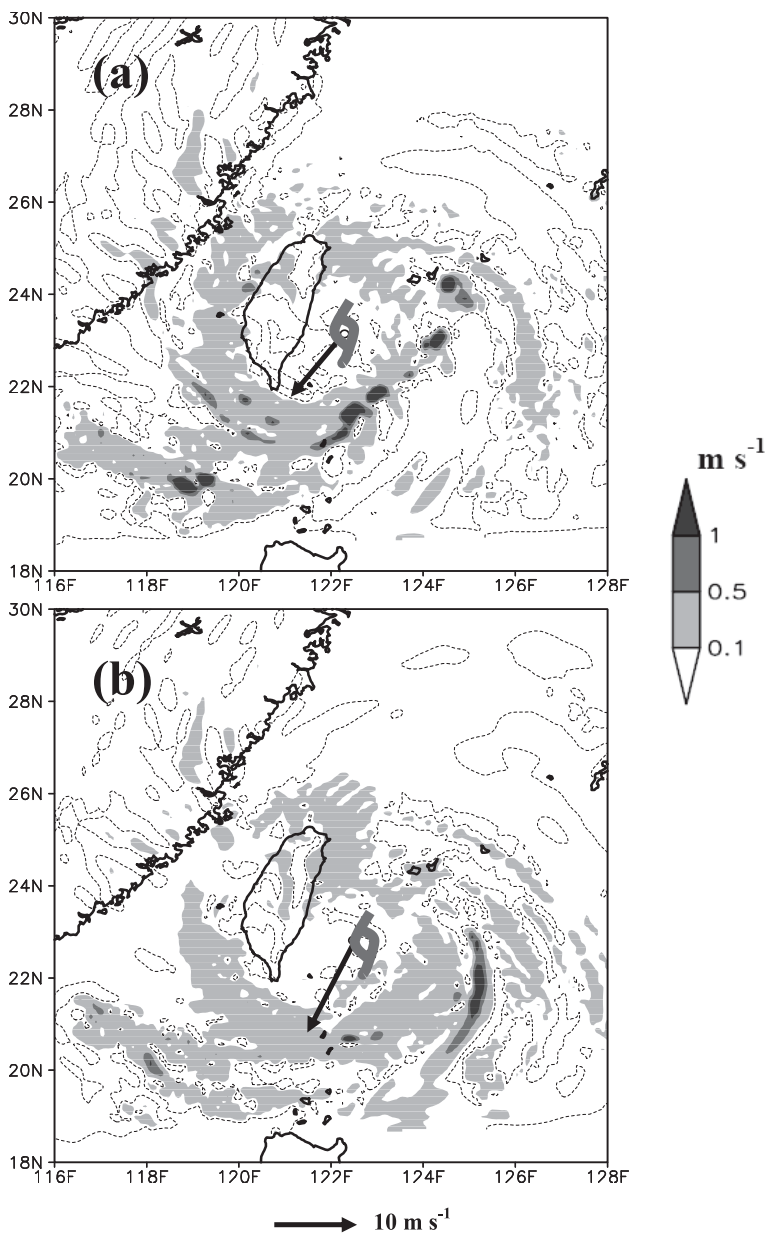

Fig. 7. Simulated $500-\mathrm{hPa}$ vertical motion at 1800 UTC 27 Jul. 2008 for Fung-wong. (a) CTRL; (b) REXP2. The areas of significant upward motion greater than $0.1 \mathrm{~ms}^{-1}$ are shaded, and the downward motion at $-0.01 \mathrm{~ms}^{-1}$ is indicated by the dashed lines. Arrows show the 6-h-averaged 850 $200-\mathrm{hPa}$ vertical wind shear vector. The center of TC is marked by a TC symbol.

(Figs. 6a, b), the CAPE also intensifies at the eastern portion of the TC circulation due to VIRV (not given).

\section{Impacts of VIRV on the Intensity and Track of the Simulated TCs}

Figures $10 \mathrm{a}-\mathrm{d}$ shows the improvement of $0-48 \mathrm{~h}$ intensity of simulated Bilis and Fung-wong with VIRV. In particular, the simulation of intensity captures most of the features of the observed intensity change. For example, the deepening-then- 


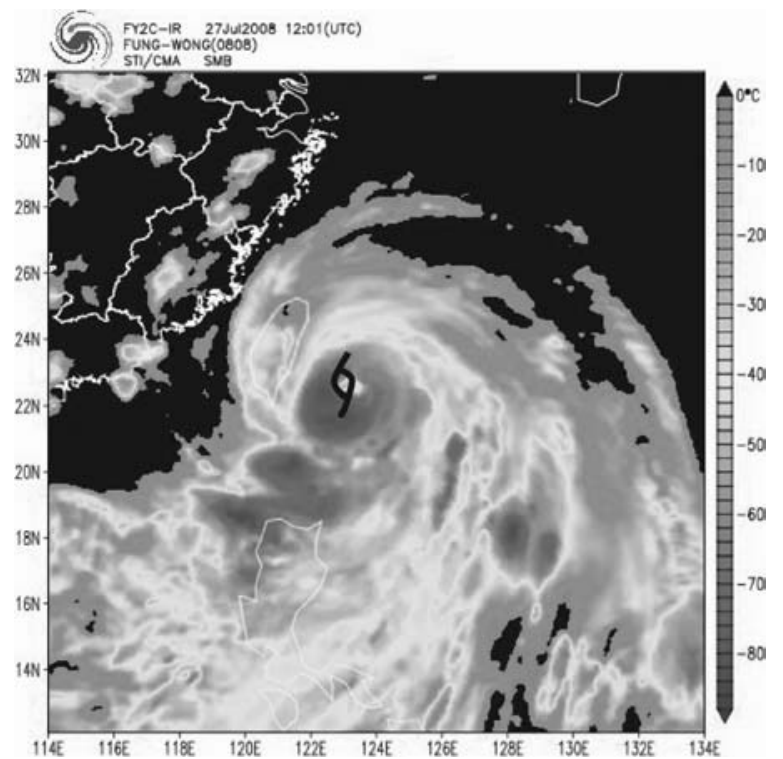

Fig. 8. Cloud-top temperature $\left({ }^{\circ} \mathrm{C}\right)$ derived from the Chinese Geostationary Infrared Satellite FY2C at 1201 UTC 27 Jul. 2008 for Fung-wong. The center of $\mathrm{TC}$ is marked by a TC symbol.

weakening phase of Bilis and the generally weakening tendency of Fung-wong are well simulated. The temporal variations of MSLP/MWS for Bilis agree well with the observations (Figs. 10a, b), except for a slower tendency of decrease/increase during the 0-24 h phase. For Fung-wong, the simulated TC intensity shows the growing agreement with the observation with model time (Figs. 10c, d, especially after $18 \mathrm{~h}$ ). Admittedly, there is discrepancy between REXP1 and REXP2. In comparison with REXP1, REXP2 enhanced the intensity of Bilis, with the most evident effect in the later (i.e., $8-\mathrm{hPa}$ decrease of MSLP at $42 \mathrm{~h}$ ). The positive effect of MRP on Fung-wong's intensity is also shown in Figs. 10c, d, with more significant improvement during 0-30 h (i.e., 5-hPa about decrease of MSLP at $18 \mathrm{~h}$ ) of model integration.

To better understand the performance of VIRV, a series of numerical experiments were further performed (ten 48-h phases of simulation are listed in Table 1). Similar to that in section 3.1, for each phase of simulation, three experiments (CTRL, REXP1, and REXP2) were conducted for comparison. The statistics of the error of track and intensity (MSLP, MWS) for each of the experiments are calculated by taking an average of the errors of

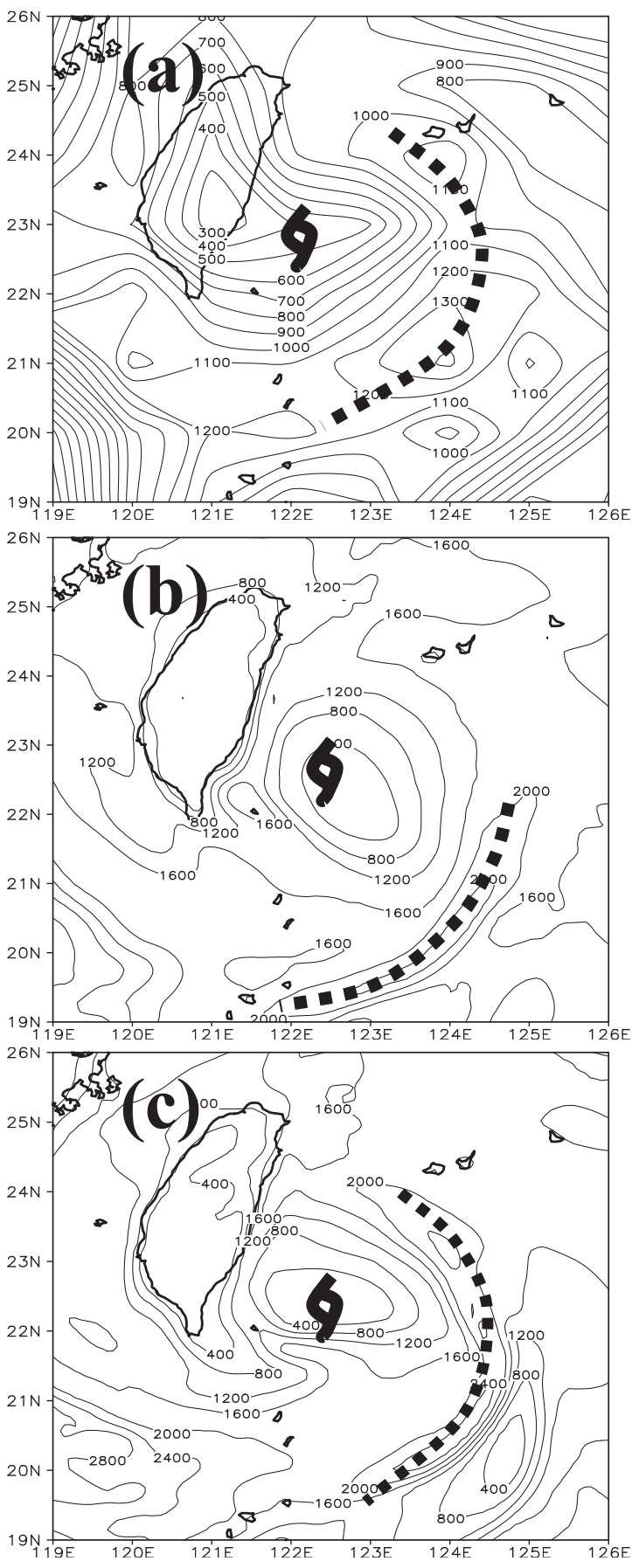

Fig. 9. The surface CAPE at 1800 UTC 27 Jul. 2008 for Fung-wong. (a) NCEP reanalysis; (b) CTRL; (c) REXP2. The interval is $100 \mathrm{~J} \mathrm{~kg}^{-1}$ in (a), and $400 \mathrm{~J} \mathrm{~kg}^{-1}$ in (b) and (c), respectively. The NCEP reanalysis are archived on a $2.5 \times 2.5$ degree lat/lon grid. The thick dashed lines indicate the distribution pattern of high CAPE that contributes to the heavy rainfall shown in Figs. $6 \mathrm{a}-\mathrm{b}$. The center of TC is marked by a TC symbol. 


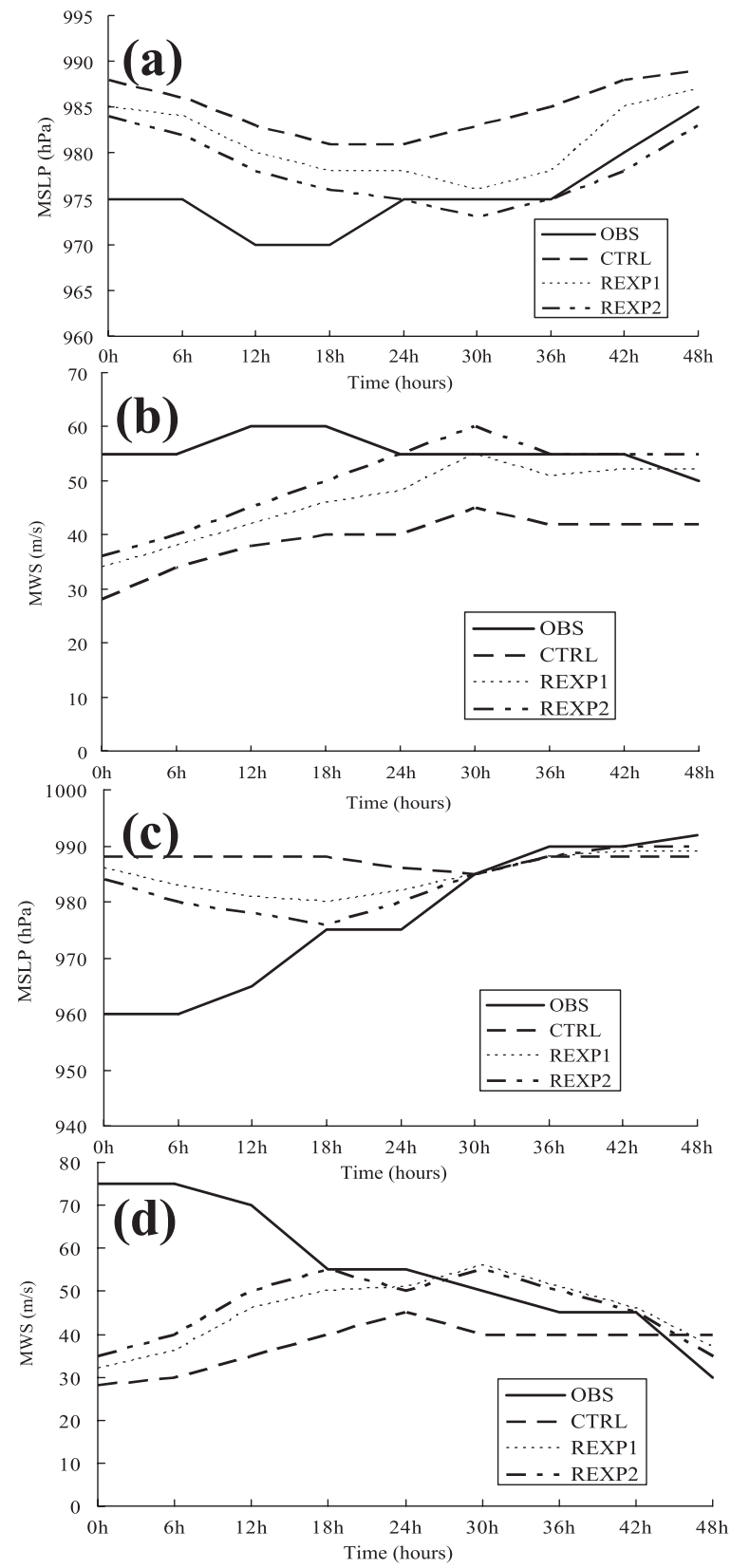

Fig. 10. TC MSLP and MWS evolution with the time at the lowest model level (approximately $50 \mathrm{~m}$ ) simulated by CTRL, REXP1, and REXP2, compared to JTWC observations (OBS). (a, c) for MSLP; $(b, d)$ for MWS. $0 \mathrm{~h}$ denotes the initial time for simulation. ( $a, b)$ for TC Bilis, and the initial time is 1200 UTC 12 Jul. 2006. (c, d) for Fung-wong, and the initial time is 1200 UTC 27 Jul. 2008.
Table 1. The simulation phases for each of the TC cases (e.g., for the simulation phase 12/12 12/14 of TC Bilis, the initial time of simulation is 1200 UTC 12 July, 2006 , the end of time of simulation is 1200 UTC 14 July, 2006; for the simulation phase $00 / 26 \sim 00 / 28$ of TC Fung-wong, the initial time of simulation is 0000 UTC 26 July, 2008, the end of time of simulation is 0000 UTC 28 July, 2006).

\begin{tabular}{lll}
\hline TC name & \multicolumn{1}{c}{ Bilis } & \multicolumn{1}{c}{ Fung-wong } \\
\hline Simulation phases & $12 / 12 \sim 12 / 14$, & $00 / 26 \sim 00 / 28$, \\
$\quad$ hour UTC/day & $00 / 13 \sim 00 / 15$, & $12 / 26 \sim 12 / 28$, \\
of month $\sim$ hour & $12 / 13 \sim 12 / 15$, & $00 / 27 \sim 00 / 29$, \\
UTC/day of & $00 / 14 \sim 00 / 16$, & $12 / 27 \sim 12 / 29$, \\
month, Month, & $12 / 14 \sim 12 / 16$, & $00 / 28 \sim 00 / 30$, \\
Year) & July, 2006 & July, 2008 \\
\hline
\end{tabular}

the ten phases (or case-averaged) at the $12 \mathrm{~h}, 24 \mathrm{~h}$, $36 \mathrm{~h}$, and $48 \mathrm{~h}$ of model integration, respectively. It shows that the errors of REXP1 and REXP2 are less than those of CTRL for all of the verified parameters (Figs. 11a, b). The largest reduction of error by VIRV is in the simulation of MWS, with $22.8 \%$ and $29.7 \%$ of reduction in REXP1 and REXP2; respectively (Fig. 11a). The improvement in MSLP is also considerable (the reduction of error is $15.7 \% / 17.1 \%$ in REXP1/REXP2, Fig. 11b). In comparison with REXP1, REXP2 improves the simulation of MWS (6.9\%) more significantly than that of MSLP (1.4\%), due to the MRP's direct effect on roughness and its subsequent impact on the change of PBL winds.

Because of the spinup of model, all the experiments present smaller MWS (Fig. 11a) and MSLP errors (Fig. 11b) at $24 \mathrm{~h}$ than at $12 \mathrm{~h}$. Assimilation alleviates the spinup problem and produces more significant improvement at $12 \mathrm{~h}$ than at $24 \mathrm{~h}$. However, the positive effect of VIRV on the intensity of simulated TC becomes more significant after $24 \mathrm{~h}$. The difference between MSLP of REXP1, REXP2, and CTRL increases with the model integration, reflecting that the simulation of MSLP at longer times is more sensitive to initial conditions than that at shorter times. This result agrees well with that of PB01 and W06. As suggested by W06, during the cycle of assimilation of wind and pressure, the assimilated wind information has a longer memory after the assimilation than the surface pressure information does. In this study, similar to W06, the relative importance of assimilating wind and pressure fields is examined on the basis of the geostrophic adjustment argument (Schubert et al. 

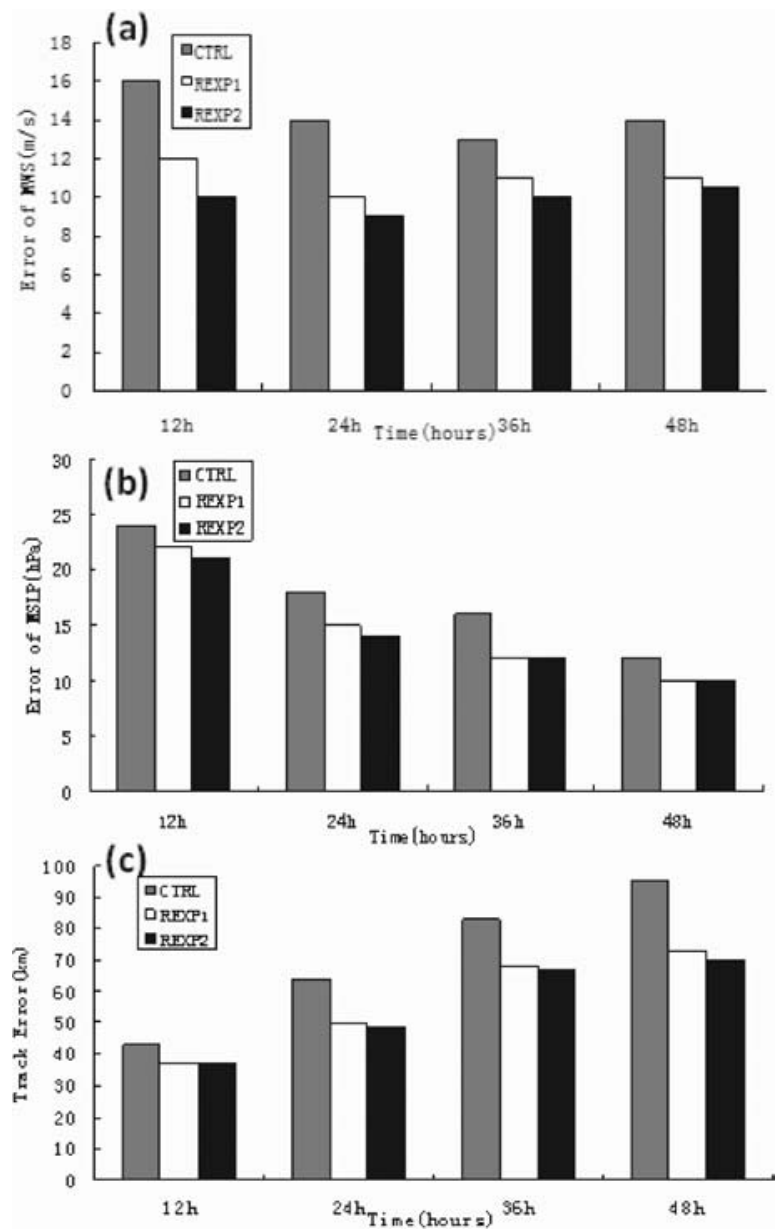

Fig. 11. The simulation error statistics caseaveraged among each of the 10 phases as described in Table 1 for the CTRL, REXP1 and REXP2 at $12 \mathrm{~h}, 24 \mathrm{~h}, 36 \mathrm{~h}$, and $48 \mathrm{~h}$ respectively. (a) MWS $\left(\mathrm{m} \mathrm{s}^{-1}\right)$; (b) MSLP (hPa); and (c) track $(\mathrm{km})$.

1980). If the radius of maximum wind $(L)$ is small compared to the local Rossby radius $L_{R}$, that is, $L / L_{R} \leq 1$, the initial tangential wind and vorticity fields would have little change (pressure adjusts to wind). Using the definition of the local Rossby radius $L_{R}=N H /(\bar{\eta} \bar{\xi})^{1 / 2}$, where $N$ is the buoyancy (Brunt-Väisälä) frequency and $H$ is the vertical scale of the motion from Shapiro and Montgomery (1993), we can estimate the value of $L / L_{R}$ in each experiment (see Table 2). Notice that the low value of $L / L_{R}(0.30)$ in this study (MT10 in Table 2) is less than that of PB01 (0.34) and slightly greater than that of W06 (0.29), favoring a geostrophic
Table 2. Estimation of the ratio of $L$ to $L_{R}, \mathrm{~PB} 01$ is based on Pu and Braun (2001), X00 denotes the result based on Xiao et al. (2000), W06 is the estimation with the definition of Wu et al. (2006), MT10 is the result of this study. Here $N$ is the static stability, $H$ is the vertical scale, $V_{\max }$ is the maximum surface wind speed, and $L$ is estimated by the radius of $V_{\max }$.

\begin{tabular}{lllll}
\hline & \multicolumn{1}{c}{ PB01 } & \multicolumn{1}{c}{ X00 } & \multicolumn{1}{c}{ W06 } & \multicolumn{1}{c}{ MT10 } \\
\hline Latitude & $18^{\circ} \mathrm{N}$ & $23^{\circ} \mathrm{N}$ & $22^{\circ} \mathrm{N}$ & $22^{\circ} \mathrm{N}$ \\
$N$ & $0.015 \mathrm{~s}^{-1}$ & $0.015 \mathrm{~s}^{-1}$ & $0.015 \mathrm{~s}^{-1}$ & $0.015 \mathrm{~s}^{-1}$ \\
$H$ & $10 \mathrm{~km}$ & $10 \mathrm{~km}^{-1}$ & $10 \mathrm{~km}^{-1}$ & $10 \mathrm{~km}$ \\
$V_{\max }$ & $20 \mathrm{~m} \mathrm{~s}^{-1}$ & $12 \mathrm{~m} \mathrm{~s}^{-1}$ & $13 \mathrm{~m} \mathrm{~s}^{-1}$ & $20 \mathrm{~km}^{-1}$ \\
$L$ & $230 \mathrm{~km}$ & $280 \mathrm{~km}$ & $330 \mathrm{~km}$ & $240 \mathrm{~km}$ \\
$L_{R}$ & $680 \mathrm{~km}$ & $1050 \mathrm{~km}$ & $1120 \mathrm{~km}$ & $810 \mathrm{~km}$ \\
$L / L_{R}$ & 0.34 & 0.27 & 0.29 & 0.30 \\
\hline
\end{tabular}

adjustment of pressure fields toward the wind fields. This might be the reason why MSLP changes slower than MWS during the simulation.

The sensitivity of the simulated TC track to VIRV is also illustrated in Figs. 11c, 12. All the experiments reproduced the processes that TCs Bilis (Fig. 12a) and Fung-wong (Fig. 12b) moving northwestward, passing through Taiwan Island, and ultimately making landfall at Fujian province in China. Nevertheless, the simulated TC tracks with the VIRV (both REXP1 and REXP2) show more consistency with the observation than those in CTRL. For instance, a northward drift of TC track is noticed in the simulation of REXP1, which could be understood by the strengthening of the southerly steering flow, with the most, medium, and least change at the lower, middle, and upper troposphere, respectively (not shown). The MRP modifies the track especially during the period that Bilis passes through Taiwan Island (Fig. 12a). For Fung-wong, MRP also improves the track simulation, with the most significant effect indicated prelandfall on Taiwan Island and Fujian Province (Fig. 12b).

To better understand the interaction between topography and TC structure and its impact on the TC intensity and track, the horizontal wind vector and relative humidity $(\mathrm{RH})$ fields at low level is examined (not given). As Fung-wong approaches Taiwan at $9 \mathrm{~h}$, evident cyclonic wind is noticed within the TC region of high RH. In the simulation of CTRL, a tongue of low-RH flow extends into the inner circulation of the TC through the north of the TC circulation. This is an early sign that the drier air in the mountainous region of Taiwan has 

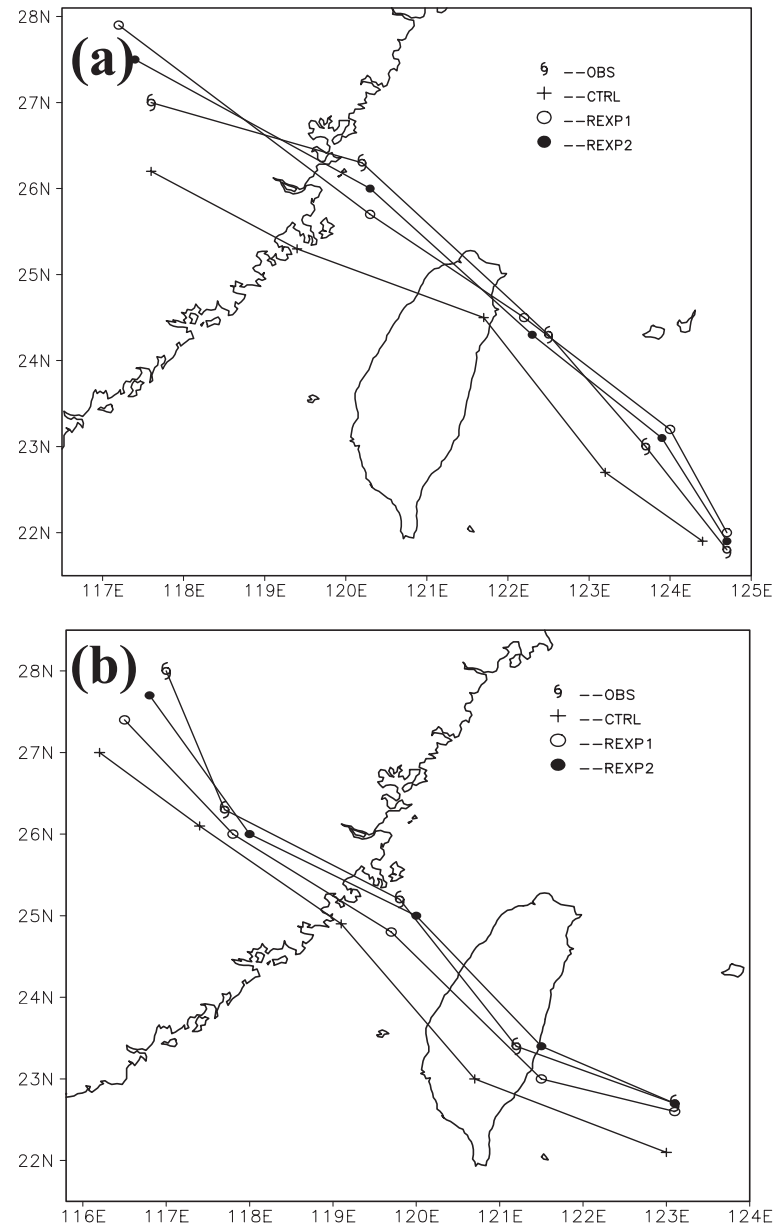

Fig. 12. Simulated and observed TC tracks. The OBS is the best track provided by JTWC. (a) TC Bilis, initial time at 1200 UTC 12 July, 2006, time interval of $12 \mathrm{~h}$. (b) TC Fung-Wong, initial time at 1200 UTC 27 July, 2008, time interval of $12 \mathrm{~h}$.

begun to interact with the TC circulation. However, in the simulation of REXP2, the distribution of high RH (above 90\%) in the northern region of TC circulation seems not evidently affected by the topography of Taiwan. As the TC simulated by REXP2 moves slower than that of CTRL, the storm center located far from the Taiwan topography and remains well organized with moist air $\mathrm{RH}$ above $90 \%$ ) to the east of Taiwan. As no additional dry air intrudes into the core region of the $\mathrm{TC}$, the maintenance of an intensive TC is favored (Figs. 10a, d). At $15 \mathrm{~h}$ of CTRL, as the TC moves across the topography of Taiwan, a large area of down- slope dry air (similar to that of Lin et al. 1999) intrudes into the northwest quardrant of the TC. After that, the intensity of the TC simulated in CTRL rapidly weakens, suggesting that the Taiwan terrain affects the storm intensity by cutting off the water supply. This result also agrees with the idealized simulation in Bender et al. (1987). In comparison, REXP2 shows no clear evidence of dry effect from the Taiwan topography (not given).

It is also interesting to note that the simulated track with VIRV (i.e., REXP1 and REXP2 in Fig. 12) turned northward prelandfall on Taiwan island, instead of passing through the southern portion of Taiwan as in CTRL. One likely answer is that this is related to the moist dynamics. In REXP2, right before landfall, the adequate moisture supply to the north of Fung-wong might favor new convection to the north quadrant of TC. The upslope lifting of the moisture-laden air then produces heavy precipitation over the north quadrant of Fungwong (not given). However in CTRL, downslope dry air is dominant at the north portion of TC, which tends to inhibit the development of vorticity and convective activity over there. We believe such an asymmetric feature, suggested by $\mathrm{Wu}$ et al. (2001), might lead to the difference in of storm tracks between CTRL and REXP2.

The zonal cross sections of vertical velocity and relative humidity fields are analyzed during the period Fung-wong hits Taiwan. At $12 \mathrm{~h}$ of integration (just 6 hours before landfall), the vertical velocity (Fig. 13a) in CTRL displays an eyewall-like structure with asymmetric updrafts around the TC center. Comparison between Figs. 13a, b indicates that the maximum vertical velocity around the TC center increases significantly with the VIRV. In comparison with the dry simulated in CTRL within the inner $150 \mathrm{~km}$ around the storm center (Fig. 13a), the air is almost saturated in REXP2 (Fig. 13b). At $18 \mathrm{~h}$ when the TC makes landfall, the vertical velocity (Figs. 13c-d) intensifies with the maximum being above $1.2 \mathrm{~m} \mathrm{~s}^{-1}$ to the west of the TC center, around which the saturated air still remains (Fig. 13d). As Fung-wong reaches central Taiwan at $18 \mathrm{~h}$, (Fig. 13c), the distribution of RH becomes more organized, while the two peaks of vertical velocity are present at $500 \mathrm{hPa}$ and $300 \mathrm{hPa}$. The eyewall in REXP2 is more contracted than that in CTRL (Figs. 13c, d), which might favor the intensification of TC (Willoughby et al. 1982; Willoughby 1990; Black and Willoughby 1992; Blackwell 2000). Moreover, as in CTRL, the maximum upward 

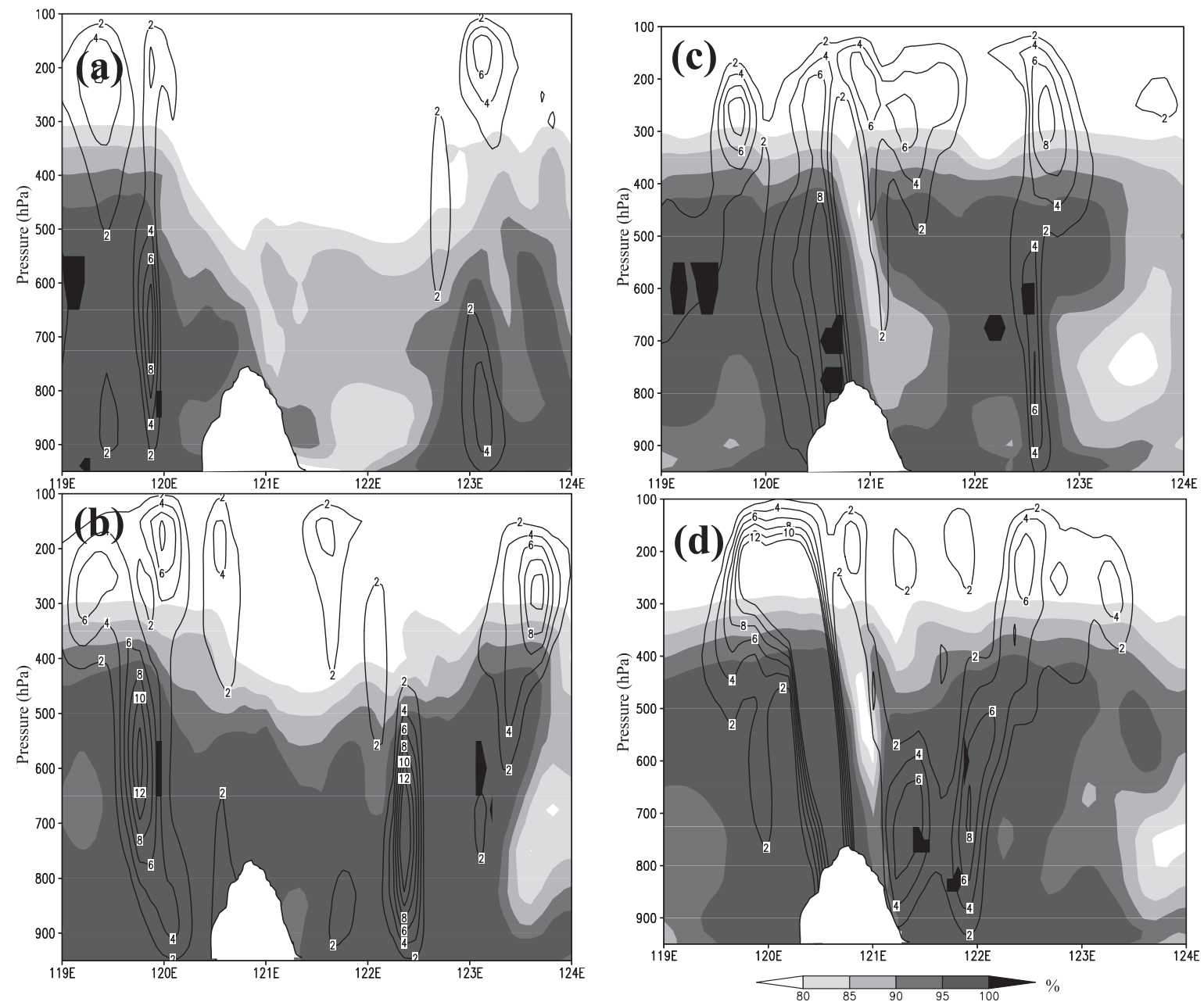

Fig. 13. The west-east cross section for the vertical velocity and relative humidity cutting through center of TC Fung-wong. (a) vertical velocity $\left(\times 10^{-1} \mathrm{~ms}^{-1}\right.$, contour interval of $\left.2 \times 10^{-1} \mathrm{~m} \mathrm{~s}^{-1}\right)$ and relative humidity (\%, shaded, interval of 5\%) simulated by CTRL at $12 \mathrm{~h}$. (b) same as (a), but for REXP2; (c) same as (a), but for $18 \mathrm{~h}$; (d) same as (b), but for $18 \mathrm{~h}$. The blank region indicates the topography of Taiwan.

motion at the west portion of TC eyewall tilts inward toward the TC center with the height, which, however, does not appear in REXP2, might prevent the downdraft within TC eyewall and the ultimate development of TC.

\section{Summary}

This study presents a new scheme, termed VIRV, for TC initialization. In VIRV, a cycled-3DVAR scheme is designed to assimilate the SLP and PBL winds retrieved from QuikSCAT data using a modified UWPBL model for the case of strong surface wind, into the WRF model in a high- resolution. In comparison with the bogus vortex techniques (i.e., BDA) that are widely used in research and operational forecasting for $\mathrm{TC}$, the VIRV attempts to reproduce a more realistic structure of TC with the joint application of PBL observation and the advanced PBL dynamical constraint instead of using a bogus vortex.

The VIRV was tested for two realistic TC Bilis (2006) and TC Fung-wong (2008) with a series of numerical experiments. It is found that the retrieved SLP and horizontal wind can be reasonably incorporated into the numerical model to recover the initial TC structure. On the basis of this, the 
VIRV enhances the low-level (high-level) convergence and inflow (divergence and outflow), warm core, as well as the merger of mesoscale vortices surrounding the core of $\mathrm{TC}$ due to the slightlyenhanced VSW. As a result, the simulated TC MWS, MSLP, and track are improved. The largest improvement is in MWS, with $22.8 \%$ reduction of error for a 48-hour simulation. The MRP for UWPBL enhanced the simulation of MWS by $6.9 \%$. The change in MSLP $(15.7 \%)$ is also considerable. In addition, the calculation of the radius of deformation indicates that in VIRV a geostrophic adjustment of pressure fields is favored toward the wind fields. This might be the reason why MSLP changes much slower than MWS in response to VIRV. Although the MRP of the UWPBL model intensifies the latent heating flux in the case of strong winds, the reduction of ocean-atmosphere PBL momentum mixing due to the MRP yields the surface sensible heating flux an approximate constant. VIRV also reduces the error of TC track about $20.1 \%$ by modifying the steering flow throughout the whole troposphere. In particular, the low-troposphere moisture structure is evidently affected by VIRV during the TC initialization, which, in association with its interaction with the perturbations over Taiwan topography, is believed to be responsible for the change in the intensity and movement of TC.

For the future study, a growing number of observations and simulations have noticed that the variation in the drag coefficient with wind speed is closely associated with the location relative to the TC center (Powell et al. 2003). Research is required to address this issue in improving the performance of MRP and PBL parameterization within VIRV. Moreover, the behavior of other advanced assimilation techniques, e.g., 4DVAR (Zou et al. 1997; Zou and Xiao 2000), Ensemble Kalman Filter (EnKF) (Houtekamer and Mitchell 1998, 2005; Anderson 2001), as well as additional observations (e.g., DOTSTAR data: Wu et al. 2007; Yamaguchi et al. 2009) based on special observational strategies (e.g., Aberson 2003) and multi-datasets (e.g., Chou et al. 2010), are also deserving to be verified in VIRV. Most importantly, much detailed physical and dynamical reasoning is desired for a comprehensive evaluation of VIRV in TC initialization, with emphasis on air-sea interaction (Black et al. 2007; Terill et al. 2007) and PBL processes (e.g., Braun and Tao 2000; Hong et al. 2006; French et al. 2007).

\section{Acknowledgements}

This study was jointly supported by the National 973 Project (No. 2009CB421500, 2009CB421502), grant from the National Natural Science Foundation (under 40705024, 40828005, 40921160382, the National Special Funding Project for Meteorology GYHY200706033, GYHY200706020 and the Institutional Fundamental Research and Operational Project of China. The authors wish to express their special gratitude to Dr. Patoux of University of Washington for his valuable suggestions on the use of the UWPBL model. The much valuable comments and suggestions of the three anonymous reviewers are greatly appreciated.

\section{References}

Aberson, S. D., 2003: Targeted observations to improve operational tropical cyclone track forecast guidance. Mon. Wea. Rev., 131, 1613-162.

Anderson, J. L., 2001: An ensemble adjustment Kalman filter for data assimilation. Mon. Wea. Rev., 129, 2884-2903.

Bender, M. A., 1997: The effect of relative flow on the asymmetric structure of the interior of hurricanes. J. Atmos. Sci. 54, 703-724.

Bender, M. A., R. E. Tuleya, and Y. Kurihara, 1987: A numerical study of the effect of island terrain on tropical cyclones. Mon. Wea. Rev., 115, 130155.

Bishop, C. H., B. J. Etherton, and S. J. Majumdar, 2001: Adaptive sampling with the ensemble transform Kalman filter. Part I: Theoretical aspects. Mon. Wea. Rev., 129, 420-436.

Black, M. L., and H. E. Willoughby, 1992: The concentric eyewall cycle of Hurricane Gilbert. Mon. Wea. Rev., 120, 947-957.

Black, M. L., J. F. Gamache, F. D. Marks Jr., C. E. Samsury, and H. E. Willoughby, 2002: Eastern Pacific hurricanes Jimena of 1991 and Olivia of 1994: The effect of vertical shear on structure and intensity. Mon. Wea. Rev., 130, 2291-2312.

Black, P. G., E. A. D'Asaro, W. M. Drennan, J. R. French, P. P. Niiler, T. B. Sanford, E. J. Terill, E. J. Walsh, and J.-A. Zhang, 2007: Air-sea exchange in hurrinces-Synthesis of observation from the coupled boundary layer air-sea transfer experiment. Bull. Amer. Metero. Soc., 88, 357-374.

Blackwell, K. G., 2000: The evolution of Hurricane Danny (1997) at landfall: Doppler-observed eyewall replacement, vortex contraction/intensification, and low-level wind maxima. Mon. Wea. Rev., 128, 4002-4016.

Braun, S. A., and W.-K. Tao, 2000: Sensitivity of highresolution simulations of Hurricane Bob (1991) to 
planetary boundary layer parameterizations. Mon. Wea. Rev., 128, 3941-3961.

Braun, S. A., and L. Wu, 2007: A Numerical study of hurricane Erin (2001). Part II: Shear and the organization of eyewall vertical motion. Mon. Wea. Rev., 135, 1179-1194.

Brown, R. A., 1970: A secondary flow model for the planetary boundary layer. J. Atmos. Sci., 27, 742-757.

Brown, R. A., 1981: Modeling the geostrophic drag coefficient for AIDJEX. J. Geophys. Res., 86, 19891994.

Brown, R. A., and L. Zeng, 1994: Estimating central pressures of oceanic midlatitude cyclones. J. Appl. Meteor., 33, 1088-1095.

Chen, S. -H., Z. Zhao, J. S. Haase, et al., 2008: A study of the characteristics and assimilation of retrieved MODIS total precipitable water data in severe weather simulations. Mon. Wea. Rev., 136, 36083628.

Chou, K.-H., and C.-C. Wu, 2008: Development of the typhoon initialization in a mesoscale modelCombination of the bogused vortex with the dropwindsonde data in DOTSTAR. Mon. Wea. Rev., 136, 865-879.

Chou, K.-H., C.-C. Wu, P.-H. Lin, and S. Majumdar, 2010: Validation of QuikSCAT wind vectors by dropwindsonde data from Dropwindsonde Observations for Typhoon Surveillance Near the Taiwan Region (DOTSTAR). J. Geophys. Res., 115, D02109, doi:10.1029/2009JD012131.

Davis, C., and L. F. Bosart, 2001: Numerical simulations of the genesis of Hurricane Diana (1984) Part I: Control simulation. Mon. Wea. Rev., 129, 18591881.

Davis, C., W. Wang, S. Y. Chen, Y. Chen, et al., 2008: Prediction of Landfalling Hurricanes with the Advanced Hurricane WRF Model. Mon. Wea. Rev., 136, 1990-2005.

DeMaria, M., and J. Kaplan, 1999: An updated statistical hurricane intensity prediction scheme (SHIPS) for the Atlantic and eastern North Pacific basins. Wea. Forecasting, 14, 326-337.

Dudhia, J., 2002: PSU/NCAR Mesoscale Modeling System Tutorial Class Notes and User's Guide: MM5 Modeling System Version 3, NCAR Tech. Note, 2002.

Emanuel, K. A., 1986: An air-sea interaction theory for tropical cyclones. Part I: Steady-state maintenance. J. Atmos. Sci., 43, 585-604.

Emanuel, K. A., 2003: A similarity hypothesis for air-sea exchange at extreme wind speeds. J. Atmos. Sci., 60, 1420-1428.

Fitzpatrick, P. J., 1997: Understanding and forecasting tropical cyclone intensity change with the Typhoon Intensity Predictions Scheme (TIPS). Wea. Forecasting, 12, 826-846.
Foster, R. C., R. A. Brown, and A. Enloe, 1999: Baroclinic modifications of midlatitude marine surface wind vectors observed by the NASA scatterometer. J. Geophys. Res., 104, 31225-31237.

Frank, W. M., and E. A. Ritchie, 1999: Effects of environmental flow upon tropical cyclone structure. Mon. Wea. Rev., 127, 2044-2061.

Franklin, J. L., S. J. Lord, S. E. Feuer, and F. D. Marks Jr., 1993: The kinematic structure of Hurricane Gloria (1985) determined from nested analysis of dropwindsonde and Doppler radar data. Mon. Wea. Rev., 121, 2433-2451.

French, J. R., W. M. Drennan, J.-A. Zhang, and P. G. Black, 2007: Turbulent fluxes in the hurricane boundary layer. Part I: momentum flux. J. Atmmos. Soc., 64, 1089-1102.

Hanley, D., J. Molinari, and D. Keyser, 2001: A composite study of the interactions between tropical cyclones and uppertropospheric troughs. Mon. Wea. Rev., 129, 2570-2584.

Hoffman, R. N., and S. M. Leidner, 2005: An introduction to the near-real-time QuikSCAT data. Wea. Forecasting, 20, 476-493.

Holton, J. R., 1992: An Introduction to Dynamic Meteorology. 3d ed. Academic Press, 511 pp.

Hong, S.-Y., and H. -L. Pan, 1996: Nonlocal boundary layer vertical diffusion in a medium-range forecast model. Mon. Wea. Rev., 124, 2322-2339.

Hong, S.-Y., J. Dudhia, and S.-H. Chen, 2004: A revised approach to ice microphysical processes for the bulk parameterization of clouds and precipitation. Mon. Wea. Rev., 132, 103-120.

Hong, S.-Y., Y. Noh, and J. Dudhia, 2006: A new vertical diffusion package with an explicit treatment of entrainment processes. Mon. Wea. Rev., 134, 2318-2341.

Houtekamer, P. L., and H. L. Mitchell, 1998: Data assimilation using an ensemble Kalman filter technique. Mon. Wea. Rev., 126, 796-811.

Houtekamer, P. L., and H. L. Mitchell, 2005: Ensemble Kalman filtering. Quart. J. Roy. Meteor. Soc., 131, 3269-3289.

Kossin, J. P., and W. H. Schubert, 2001: Mesovortices, polygonal flow patterns, and rapid pressure falls in hurricane-like vortices. J. Atmos. Sci., 58, 21962209.

Krishnamurti, T. N., J. Xue, H. S. Bedi, K. Ingles, and D. Oosterhof, 1991: Physical initialization for numerical weather prediction over the tropics. Tellus, 43AB, 53-81.

Krishnamurti, T. N., H. S. Bedi, G. D. Rohaly, D. K. Oosterhof, R. C. Torres, E. Williford, and N. Surgi, 1996: Physical initialization. J. Atmos. Oceans, 35, 369-398.

Krishnamurti, T. N., W. Han, and D. K. Oosterhof, 1998: Sensitivity of hurricane intensity forecasts to 
physical initialization. Meteor. Atmos. Phys., 65 171-181.

Kurihara, Y., M. A. Bender, R. E. Tuleya, and R. J. Ross, 1990: Prediction experiments of Hurricane Gloria (1985) using a multiply nested movable mesh model. Mon. Wea. Rev., 118, 2185-2198.

Kurihara, Y., M. A. Bender, R. E. Tuleya, and R. J. Ross, 1995: Improvements in the GFDL hurricane prediction system. Mon. Wea. Rev., 123, 2791-2801.

Leslie, L. M., and G. J. Holland, 1995: On the bogussing of tropical cyclones in numerical models-A comparison of vortex profiles. Meteor. Atmos. Phys. 56, 101-110.

Lin, Y. -L., J. Han, D. W. Hamilton, and C.-Y. Huang, 1999: Orographic influence on a drifting cyclone. $J$. Atmos. Sci., 56, 534-562.

Liu, W. T., K. B. Katsaros, and J. A. Businger, 1979: Bulk parameterization of air-sea exchange of heat and water vapor including the molecular constraints at the interface. J. Atmos. Sci., 36, 1722 1735.

Liu, D. C., and J. Nocedel, 1989: On the limited memory BFGS method for large scale optimization. Math. Program., 45, 503-528.

Ma, L. -M., Z. Qin, Y. Duan, B. -Y. Du, 2002: Numerical experiments for the impact of ocean heat flux on the development of cyclones in East China Sea. Acta Oceanol. Sinica (in Chinese), 24, 112-121.

Ma, L. -M., Z. Qin, Y. Duan, et al., 2006: Impacts of TRMM SRR assimilation on the numerical prediction of tropical cyclone. Acta. Oceanol. Sinica, 25, $14-26$.

Ma, L. -M., J. C. L. Chan, N. Davidson, and J. Turk, 2007: Initialization with diabatic heating from satellite-derived rainfall. Atmos. Res., 85, 148-158.

Makin, V. K., 2005: A note on the drag of the sea surface at hurricane winds. Bound.-Layer Meteor., 115, 169-176.

Marks, F., Jr., R. A. Houze Jr., and J. F. Gamache, 1992: Dualaircraft investigation of the inner core of Hurricane Norbert. Part I: Kinematic structure. J. Atmos. Sci., 49, 919-942.

Miller, D. K., and K. B. Katsaros, 1992: Satellite-derived surface latent heat fluxes in a rapidly intensifying marine cyclone, Mon. Wea. Rev., 120, 1093-1107.

Montgomery, M. T., and J. Enagonio, 1998: Tropical cyclogenesis via convectively forced vortex Rossby waves in a three-dimensional quasigeostrophic model. J. Atmos. Sci., 55, 3176-3207.

Montgomery, M. T., V. A. Vladimirov, and P. V. Denissenko, 2002: An experimental study on hurricane mesovortices. J. Fluid Mech., 471, 1-32.

Moon, I.-J., T. Hara, I. Ginis, S. E. Belcher, and H. Tolman, 2004a: Effect of surface waves on air-sea momentum exchange. Part I: Effect of mature and growing seas. J. Atmos. Sci., 61, 2321-2333.
Moon, I.-J., I. Ginis, and T. Hara, 2004b: Effect of surface waves on air-sea momentum exchange. Part II: Behavior of drag coefficient under tropical cyclones. J. Atmos. Sci., 61, 2334-2348.

Moon, I.-J., I. Ginis, and T. Hara, 2004c: Effect of surface waves on Charnock coefficient under tropical cyclones. Geophys. Res. Lett., 31, L20302, Doi:10.1029/2004GL020988.

Moon, I.-J., I. Ginis, T. Hara, and B. Thomas, 2007: A physics-based parameterization of air-sea momentum flux at high wind speeds and its impact on hurricane intensity predictions. Mon. Wea. Rev., 135, 2869-2878.

Neldar, J. A., and R. Mead, 1965: A simplex method for function minimization. Comput. J., 7, 308-313.

Noh, Y., W. G. Cheon, S. Y. Hong, and S. Raasch, 2003: Improvement of the K-profile model for the planetary boundary layer based on large eddy simulation sata. Bound.-Layer Meteor., 107, 401427.

Parrish, D. F., and J. C. Derber, 1992: The National Meteorological Center's Spectral Statistical Interpolation analysis system. Mon. Wea. Rev., 120, $1747-$ 1763.

Paterson, L. A., N. B. Hanstrum, N. E. Davidson, and H. C. Weber, 2005: Influence of environmental vertical wind shear on the intensity of hurricanestrength tropical cyclones in the Australian region. Mon. Wea. Rev., 133, 3644-3660.

Patoux, J., 2000: UWPBL 3.0, The University of Washington Planetary Boundary Layer (UWPBL) Model. Tech. Note, University of Washington, 54 pp.

Patoux, J., and R. A. Brown, 2002: A gradient wind correction for surface pressure fields retrieved from scatterometer winds. J. Appl. Meteor., 41, 133143.

Patoux, J., R. C. Foster, and R. A. Brown, 2003: Global pressure fields from scatterometer winds. J. Appl. Meteor., 42, 813-826.

Patoux, J., R. C. Foster, and R. A. Brown, 2008: An evaluation of scatterrometer-derived oceanic surface pressure fields. J. Appl. Meteor. Climat., 47, 835-852.

Powell, M. D., P. J. Vickery, and T. A. Reinhold, 2003: Reduced drag coefficient for high wind speeds in tropical cyclones. Nature, 422, 279-283.

$\mathrm{Pu}, \mathrm{Z} . \mathrm{X}$., and S. A. Braun, 2001: Evaluation of bogus vortex techniques with four-dimensional variational data assimilation. Mon. Wea. Rev., 129, 2023-2039.

Reasor, P. D., M. T. Montgomery, F. D. Marks Jr., and J. F. Gamache, 2000: Low-wavenumber structure and evolution of the hurricane inner core observed by airborne dual-Doppler radar. Mon. Wea. Rev., 128, 1653-1680. 
Ritchie, E. A., and G. J. Holland, 1997: Scale interactions during the formation of Typhoon Irving. Mon. Wea. Rev., 125, 1377-1396.

Rogers, R., S. Chen, J. Tenerelli, and H. Willoughby, 2003: A numerical study of the impact of vertical shear on the distribution of rainfall in Hurricane Bonnie (1998). Mon. Wea. Rev., 131, 1577-1599.

Schubert, W. H., J. J. Hack, P. L. Silva Dias, and S. R. Fulton, 1980: Geostrophic adjustment in an axisymmetric vortex. J. Atmos. Sci., 37, 14641484.

Schubert, W. H., M. T. Montgomery, R. K. Taft, T. A. Guinn, S. R. Fulton, J. P. Kossin, and J. P. Edwards, 1999: Polygonal eyewalls, asymmetric eye contraction, and potential vorticity mixing in hurricanes. J. Atmos. Sci., 56, 1197-1223.

Shapiro, L. J., and M. T. Montgomery, 1993: A threedimensional balance theory for rapidly rotating vortices. J. Atmos. Sci., 50, 3322-3335.

Skamarock, W. C., J. B. Klemp, J. Dudhia, D. O. Gill, D. M. Barker, W. Wang, and J. G. Powers, 2005: A description of the Advanced Research WRF version 2. NCAR Tech. Note TN-4681STR, $88 \mathrm{pp}$.

Smith, S. D., 1988: Coefficients for sea surface wind stress, heat flux, and wind profiles as a function of wind speed and temperature, J. Geophys. Res., 93(C12), 15467-15472.

Stevens, B., J. Duan, J. C. McWilliams, M. Münnich, and J. D. Neelin, 2002: Entrainment, Rayleigh friction, and boundary layer winds over the tropical Pacific. J. Climate, 15, 30-44.

Stiles, B. W., and S. Yueh, 2002: Impact of rain on spaceborne Kuband scatterometer data. IEEE Trans. Geosci. Remote Sens., 40, 1973-1983.

Terill, E. J. Walsh, and J.-A. Zhang, 2007: Air-sea exchange in hurrinces-Synthesis of observation from the coupled boundary layer air-sea transfer experiment. Bull. Amer. Metero. Soc., 88, 357374.

Tang, X. D., and Z.-M. Tan, 2006: Boundary-layer wind structure in a landfalling tropical cyclone. $A d v$. Atmos. Sci., 23, 737-749.

Wentz, F., and D. K. Smith, 1998: Rain effect on NSCAT sigma-0 measurements. Proc. NSCAT/ Quikscat Science Team Meeting, Kona, HI, Jet Propulsion Laboratory.

Willoughby, H. E., J. A. Clos, and M. G. Shoreibah, 1982: Concentric eyewalls, secondary wind maxima, and the evolution of the hurricane vortex. $J$. Atmos. Sci., 39, 395-411.
Willoughby, H. E., F. D. Marks Jr., and R. J. Feinberg, 1984: Stationary and moving convective bands in hurricanes. J. Atmos. Sci., 41, 3189-3211.

Willoughby, H. E., 1990: Temporal changes in the primary circulation in tropical cyclones. J. Atmos. Sci., 47, 242-264.

Wu, C.-C., 2001: Numerical simulation of Typhoon Gladys (1994) and its interaction with Taiwan terrain using GFDL hurricane model. Mon. Wea. Rev., 129, 1533-1549.

Wu, C.-C., K.-H. Chou, Y. Wang, and Y.-H. Kuo, 2006: Tropical cyclone initialization and prediction based on four-dimensional variational data assimilation. J. Atmos. Sci., 63, 2383-2395.

Wu, C.-C., K.-H. Chou, P.-H. Lin, S. D. Aberson, M. S. Peng, and T. Nakazawa, 2007: The impact of dropwindsonde data on typhoon track forecasts in DOTSTAR. Wea. Forecasting, 22, 1157-1176.

Xiao, Q., X. Zou, and B. Wang, 2000: Initialization and Simulation of a Landfalling Hurricane Using a Variational Bogus Data Assimilation Scheme. Mon. Wea. Rev., 128, 2252-2269.

Xiao, Q., Y. -H. Kuo, Y. Zhang, D. M. Barker, 2006: A tropical cyclone bogus data assimilation scheme in the MM5 3D-Var system and numerical experiments with typhoon Rusa (2002) near landfall. $J$. Meteor. Soc. Japan, 84, 671-689.

Xiao, Q., L. Chen, and X. Zhang, 2009: Evaluations of BDA Scheme Using the Advanced Research WRF (ARW) Model. J. Appl. Meteorol. Climat., 48, 680-689.

Xu, J., Q. Zhang, X. Zhang, S. Wang, and F. Lu, 2006: Status of Operational AMVs from FY-2C, Proceedings of the 8th International Winds, Beijing, China, 24-28 April, 2006.

Yamaguchi, M., T. Iriguchi, T. Nakazawa, and C.-C. $\mathrm{Wu}, 2009$ : An observing system experiment for Typhoon Conson (2004) using a singular vector method and DOTSTAR data. Mon. Wea. Rev., 137, 2801-2816.

Zhao, Q., and Y. Jin, 2008: High-resolution radar data assimilation for Hurricane Isabel (2003) at landfall. Bull. Amer. Meteor. Soc., 89, 1355-1372.

Zou, X., F. Vandenberghe, M. Pondeca, and Y. -H. Kuo, 1997: Introduction to adjoint techniques and the MM5 Adjoint Modeling System. NCAR Tech. Note NCAR/TN-435+STR, $110 \mathrm{pp}$.

Zou, X., and Q. Xiao, 2000: Studies on the initialization and simulation of a mature hurricane using a variational bogus data assimilation scheme. $J$. Atmos. Sci, 57, 836-860. 